\title{
Comparison of a Spectral Microphysics and a Two-Moment Cloud Scheme: Numerical Simulations of the Cloud-Topped Marine Boundary Layer
}

\author{
Andreas Bott ${ }^{1}$ \\ Received: 15 August 2019 / Accepted: 16 January 2020 / Published online: 28 February 2020 \\ (c) The Author(s) 2020
}

\begin{abstract}
A comparison between the spectral microphysics cloud scheme (MiStra) and the parametrized cloud scheme (PaStra) is presented. The main feature of MiStra consists of the treatment of aerosol particles, cloud droplets, and drizzle particles in a joint two-dimensional particle size distribution, whereas PaStra consists of a two-moment scheme for cloud droplets combined with a one-moment scheme for drizzle. Both cloud schemes have been implemented in a single-column model of the cloud-topped marine boundary layer. Numerical sensitivity studies are presented demonstrating that MiStra is capable of simulating in great detail the major cloud microphysical processes occurring in low-level stratiform clouds. While in MiStra no empirical parameter is available to tune the model, the empirical model parameters of PaStra have been tuned by means of the MiStra model results. By comparing the numerical results of PaStra with those of MiStra it is found that PaStra simulates the overall characteristics of the cloud-topped marine boundary layer quite well. At the same time, however, the effects of single cloud microphysical processes differ substantially from those of MiStra. Finally, it is shown that even in PaStra the inclusion of all major cloud microphysical processes is mandatory in order to obtain appropriate results.
\end{abstract}

Keywords Marine boundary layer $\cdot$ MiStra $\cdot$ Parametrized cloud microphysics $\cdot$ PaStra . Spectral cloud microphysics

\section{Introduction}

The treatment of cloud processes is an inevitable and integral part of all numerical weather prediction (NWP) models. In these models, it is common practice to use different parametrization schemes for grid-scale stratiform and subgrid-scale convective clouds. Moreover, the parametrization schemes may differ regarding the inclusion of liquid water, ice, or mixed phase processes occurring within the clouds. For the numerical simulation of the mid-latitude cloud-topped marine boundary layer (MBL), it is usually sufficient to apply a grid-scale warm-

Andreas Bott

a.bott@uni-bonn.de

1 Institute of Geosciences, University of Bonn, Bonn, Germany 
cloud scheme that ignores ice and mixed-phase cloud processes. The numerical simulation of marine stratiform boundary-layer clouds is of particular importance not only for weather prediction but also for climate studies, since these clouds are often very persistent thereby covering large areas of the oceans. Owing to their high albedo they have a strong negative effect on the Earth's radiation budget (Klein and Hartmann 1993).

The existing cloud models may be subdivided into two groups: the spectral and the bulk microphysics schemes. In the spectral approach, cloud droplets are represented by a particle size distribution, and for each droplet size class (bin) a separate prognostic equation is solved. In a warm-cloud scheme the microphysical processes to be considered in this prognostic equation include the activation of aerosol particles to form cloud droplets, their subsequent diffusional growth, as well as the formation of precipitation particles by collision and coalescence of the cloud droplets. Bulk microphysics cloud schemes do not describe cloud processes in detail. Instead, they only simulate the time evolution of bulk cloud characteristics, such as cloud thickness, total cloud water content, liquid water path, precipitation rate, and others. Of course, in both cloud schemes, dynamical processes, that is advection, turbulent mixing, and gravitational settling of the hydrometeors, have to be accounted for as well.

In the literature, a large number of spectral and bulk microphysics cloud schemes of different complexity exists ranging from simple one- or two-moment schemes with the cloud-water mixing ratio, or both the cloud-water mixing ratio and the total droplet number concentration, as prognostic variables (e.g., Kessler 1969; Sundqvist et al. 1989; Khairoutdinov and Kogan 2000; Milbrandt and Yau 2005; Morrison et al. 2005; Morrison and Gettelman 2008; Lim and Hong 2010), to spectral approaches where cloud and raindrops are represented by particle size distributions (e.g., Clark 1973; Kogan 1991; Lynn et al. 2005; Khain et al. 2009, 2015). Grabowski et al. (2019) present a comprehensive overview of progress in the field of cloud microphysical parametrizations made during the last decades. Several studies exist dealing with a comparison of spectral versus bulk microphysics cloud schemes (e.g., Khain et al. 2009; Fan et al. 2012; Lee and Baik 2018). These investigations, which focus on situations with deep cumulus convection, indicate that bin microphysics schemes are clearly superior to bulk models yielding more realistic representations of all relevant cloud processes. At the same time, however, it is also emphasized that, owing to the extremely high computational effort of bin microphysics schemes, they are presently not used in NWP or climate models.

In the present study, we compare the spectral microphysics stratus model (MiStra) (Bott et al. 1996), and the stratus model with parametrized cloud microphysics (PaStra). MiStra and PaStra are extended versions of the microphysical fog model (MiFog) (Bott et al. 1990), and the parametrized fog model (PaFog) (Bott and Trautmann 2002), including now the process of drizzle formation. A unique feature of the MiStra model is given by its treatment of aerosol particles, cloud droplets, and drizzle particles in a joint two-dimensional particle size distribution with the aerosol and water mass as independent variables. This particle spectrum is subdivided into some thousand bins of different aerosol and water mass, thus enabling a very detailed simulation of the major cloud microphysical processes, i.e. the activation of aerosol particles to form cloud droplets, the diffusional growth of the activated cloud droplets, and the formation of drizzle particles by collision/coalescence processes. In contrast to this, in the parametrized model PaStra, a two-moment scheme for cloud droplets combined with a one-moment approach for drizzle formation is applied. Hence, prognostic equations are solved for the total number concentration of cloud droplets and the mixing ratios of cloud and drizzle water.

Since the MiStra model is computationally very expensive, it has not yet been implemented in three-dimensional atmospheric models. However, several applications exist where 
the model has been combined with a chemical reaction mechanism simulating in a singlecolumn model version gas and aqueous phase chemical reactions during a fog event (Bott and Carmichael 1993) and the cloud-topped MBL (von Glasow et al. 2002; Pechtl et al. 2007; Bobrowski et al. 2007, 2015). The PaFog model, on the other hand, has already been implemented in three-dimensional dynamical models describing there the spatio-temporal evolution of fog events (Masbou 2008; Müller et al. 2010; Kim et al. 2019).

For comparison of the PaStra with the MiStra model, both models have been merged to a single one-dimensional (height-dependent) planetary boundary-layer (PBL) model describing the time evolution of the cloud-topped MBL. For brevity, the PBL model version using the spectral microphysical cloud scheme will henceforth be called MiStra, while the PBL model version using the parametrized cloud scheme will be denoted PaStra. Of course, we are aware of the fact that with a single-column PBL model, which is equivalent to the assumption of horizontal homogeneity of all thermodynamic variables, a numerical simulation of realistic fog and stratus events is usually hardly possible. However, this treatment enables a comparison of the performance of the parametrized microphysics approach of PaStra with the spectral microphysical approach of MiStra so that the use of PaStra in three-dimensional NWP or climate models may be justified. Moreover, following the argumentations of Smith et al. (2018), even with a computationally very efficient single-column model the interaction of different physical processes occurring during the life cycle of fog and low-level clouds can be adequately simulated. We believe that our findings with the single-column PBL model are for the most part transferable to three-dimensional NWP models, since in these models physical processes, such as turbulence, radiative transfer, and cloud microphysics are usually parametrized separately in each vertical grid column.

In the following section, we present a short overview of the governing model equations. Since here we are not able to discuss all model equations in detail, we refer the reader to corresponding earlier literature (Bott et al. 1990, 1996; Bott and Trautmann 2002). Section 3 presents a detailed description and discussion of the numerical results, while a summary and concluding remarks are given in Sect. 4.

\section{Model Description}

\subsection{Dynamics}

The dynamical part of the model consists of a set of prognostic equations for the horizontal wind field with velocity components $(u, v)$, the potential temperature $\theta$, and the specific humidity $q_{v}$ as given by

$$
\begin{aligned}
\frac{\partial u}{\partial t} & =\frac{\partial}{\partial z}\left(k_{m} \frac{\partial u}{\partial z}\right)-w \frac{\partial u}{\partial z}+f\left(v-v_{g}\right), \\
\frac{\partial v}{\partial t} & =\frac{\partial}{\partial z}\left(k_{m} \frac{\partial v}{\partial z}\right)-w \frac{\partial v}{\partial z}-f\left(u-u_{g}\right), \\
\frac{\partial \theta}{\partial t} & =\frac{\partial}{\partial z}\left(k_{h} \frac{\partial \theta}{\partial z}\right)-w \frac{\partial \theta}{\partial z}-\left(\frac{p_{0}}{p}\right)^{\frac{R}{c_{p}}} \frac{1}{c_{p} \rho}\left(\frac{\partial E_{n}}{\partial z}-L C\right), \\
\frac{\partial q}{\partial t} v & =\frac{\partial}{\partial z}\left(k_{h} \frac{\partial q}{\partial z}\right)-w \frac{\partial q_{v}}{\partial z}-\frac{C}{\rho} .
\end{aligned}
$$


The first terms on the right-hand side (r.h.s.) of these equations describe the turbulent mixing with exchange coefficients $\left(k_{m}, k_{h}\right)$ for momentum and heat, where the values of $\left(k_{m}, k_{h}\right)$ are diagnostically calculated by means of the level-2.5 turbulence closure scheme of Mellor and Yamada (1982). In this approach the exchange coefficients are determined as functions of the turbulence kinetic energy, for which a prognostic equation is solved. More details on the turbulence scheme can be found in Mellor and Yamada (1982) or in Bott et al. (1996).

The second terms on the r.h.s. of Eq. 1 denote the large-scale subsidence with the vertical component $w$ of the wind field. It is noteworthy that by reason of mass conservation, in a one-dimensional model large-scale subsidence should not occur, that is $w=0$ in (1). However, without this forcing term a reasonable simulation of fog or stratiform clouds with a one-dimensional model would be impossible (see, e.g., Driedonks and Duynkerke 1989; Bott et al. 1996; Wærsted et al. 2019).

The last term in Eqs. 1a, $1 \mathrm{~b}$ represents the Coriolis force together with the pressure gradient force whereby $f$ is the Coriolis parameter and $\left(u_{g}, v_{g}\right)$ are the components of the geostrophic wind. The term $E_{n}$ occurring in the prognostic equation for $\theta$ is the net radiative flux density, here obtained from the radiation scheme presented in Loughlin et al. (1997). In this $\delta$-two stream approximation, which is based on the radiation scheme of $\mathrm{Fu}$ (1991) and Fu and Liou (1992), for the calculation of the atmospheric radiative transfer the solar and the infrared spectral regions are subdivided into six and twelve sub-intervals, respectively. A special feature of the radiation scheme consists in the application of the $k$-distribution method for the calculation of the radiative absorption by atmospheric gases (Lacis and Oinas 1991). Finally, the last term in the prognostic equations for $\theta$ and $q_{v}$ denotes condensation/evaporation processes whereby $L$ is the latent heat of condensation and $C$ is the condensation rate. All other terms occurring in (1) have their usual meaning.

\subsection{Cloud Microphysics}

In the present PBL model, cloud microphysical processes may be considered by choosing either the spectral cloud microphysics (MiStra) or the parametrized cloud scheme (PaStra). In MiStra, cloud processes are described in great detail by calculating the time evolution of a joint two-dimensional spectral size distribution for aerosol particles and cloud droplets, while in PaStra a two-moment scheme is applied calculating the total number concentration of cloud droplets and the cloud water content. In each grid cell of the vertical grid column, condensation/evaporation as well as collision/coalescence are calculated as functions of the average relative humidity, i.e. subgrid-scale variations of the relative humidity within a single grid cell are ignored. It is also noteworthy that for a particular model run it is possible to choose one of the two cloud schemes in such a way that all other model parts remain unchanged.

\subsubsection{The Cloud Scheme with Spectral Microphysics}

The spectral cloud microphysics approach of MiStra is based on the microphysical fog model MiFog of Bott et al. (1990) and the extensions of this model to the microphysical stratus model (see, e.g., Bott et al. 1996; Bott 1997, 2001). Here, aerosol particles and cloud droplets are combined in a joint two-dimensional size distribution $f\left(m_{a}, m_{w}\right)$ with the dry aerosol mass $m_{a}$ and the liquid water mass $m_{w}$ as independent variables. The aerosol and liquid-water mass spectra are logarithmically equidistant subdivided into $70 \times 70$ bins yielding radii of the dry aerosol particles and the total particles in the ranges $0.01-10 \mu \mathrm{m}$ and $0.01-550 \mu \mathrm{m}$, 
respectively. Hence, the time evolution of the particle spectrum is described by solving a set of 4900 prognostic equations of the form

$$
\begin{aligned}
\frac{\partial f\left(m_{a}, m_{w}\right)}{\partial t}= & \frac{\partial}{\partial z}\left(k_{m} \frac{\partial f\left(m_{a}, m_{w}\right)}{\partial t}\right)-\left\{w+w_{t}\left(m_{a}, m_{w}\right)\right\} \frac{\partial f\left(m_{a}, m_{w}\right)}{\partial t} \\
& -\frac{\partial}{\partial r}\left\{\dot{r} f\left(m_{a}, m_{w}\right)\right\}+\left(\frac{\partial f\left(m_{a}, m_{w}\right)}{\partial t}\right)_{c o a} \cdot
\end{aligned}
$$

The first two terms on the r.h.s. describe turbulent mixing processes and the vertical displacement of $f\left(m_{a}, m_{w}\right)$ as caused by the large-scale subsidence $w$ together with the gravitational settling of the particles with terminal velocity $w_{t}\left(m_{a}, m_{w}\right)$. This quantity is calculated according to Beard (1976). The third term denotes the modification of the particle spectrum due to diffusional growth of the particles during condensation/evaporation. The droplet growth velocity $\dot{r}$ is calculated following Davies (1985). In this form of $\dot{r}$, the impact of the atmospheric radiation field on the diffusional growth of the cloud droplets is explicitly considered (see also Bott et al. 1990, 1996). Finally, the last term in Eq. 2 represents collision/coalescence processes affecting the particle spectrum. These processes are accounted for by solving the stochastic collection equation (e.g., Pruppacher and Klett 1997). A detailed description of the numerical solution of the stochastic collection equation for the special case of a twodimensional particle space is presented in Bott (2001).

It should be emphasized that with the approach of a joint two-dimensional particle spectrum for unactivated aerosols and activated droplets, in MiStra the activation process of aerosol particles to form cloud droplets is explicitly simulated, that is the movement of each particle along the stable and unstable part of the Köhler curve is directly calculated as a function of the relative humidity. This holds in subsaturated and likewise in supersaturated environments. Moreover, drizzle particles, which may be formed by collision/coalescence of cloud droplets, are also included in this joint particle distribution. Hence, from the mathematical point of view, the model does not distinguish between unactivated aerosol particles, cloud droplets, and drizzle particles.

Nonetheless, in order to enable a comparison between MiStra and PaStra, in the numerical results to be presented in the next section, a subdivision of the particle spectrum has been performed in such a way that all particles with total radius smaller than $r_{1}=1 \mu \mathrm{m}$ are denoted as (interstitial) aerosol particles, particles with a radius between $r_{1}$ and $r_{2}=40$ $\mu \mathrm{m}$ refer to cloud droplets, while all particles with a radius exceeding $r_{2}$ are called drizzle particles. According to this subdivision the term cloud water content refers to the water mass of all cloud droplets, the water mass of all drizzle particles is denoted as drizzle water content while the total liquid water content is given by the sum of the cloud and drizzle water mass. The values of the two radii $\left(r_{1}, r_{2}\right)$ are somehow arbitrarily chosen and not very strongly based on microphysical processes. The reason for their choice is given in the next section.

In MiStra the extinction of shortwave and longwave radiation by the particles is calculated as a function of the time dependent radiation parameters of the spectral particle size distribution. These parameters are obtained by utilizing the results of an extensive series of Mie calculations where the radiation parameters of single particles with different fractions of aerosol and water mass have been determined and stored in look-up tables. Utilizing these tables, in each spectral region of the radiation scheme the actual radiation parameters of the particles are given by evaluating corresponding integrals over the particle size distribution. For more details of this approach, see Bott et al. (1990).

From the above model equations it is concluded that in MiStra no empirical parameters are available to tune the model. In contrast to this, in PaStra all microphysical processes are strongly parametrized yielding in this scheme various empirical model parameters that may 
be adjusted to optimize the model results. Hence, the empirical model parameters of PaStra as presented in the following section have been tuned based on numerous sensitivity studies and comparison with corresponding MiStra results.

\subsubsection{The Cloud Scheme with Parametrized Microphysics}

It is quite obvious that the spectral cloud microphysics scheme of MiStra is numerically very expensive in terms of computer memory and CPU time usage, thus presently prohibiting the implementation of the scheme in a three-dimensional NWP model. As an alternative to the detailed microphysics approach, Bott and Trautmann (2002) introduced the parametrized model for radiation fog PaFog. This approach has already successfully been implemented in three-dimensional NWP models (see, e.g., Masbou 2008; Müller et al. 2010). In PaFog the detailed spectral cloud microphysics approach of MiFog has been replaced by a numerically very efficient parametrization scheme for fog microphysics, which is based on Nickerson et al. (1986) and Chaumerliac et al. (1987).

In the original form of PaFog, drizzle formation by collision/coalescence of cloud droplets has been ignored. For the numerical simulation of radiation fogs this simplification might be justifiable since it is to be expected that during fog events drizzle plays only a minor role. However, since the present PBL model is used for the simulation of low-level stratiform clouds, the parametrized cloud scheme of PaStra has been extended by a simple parametrization for the treatment of drizzle formation. In accordance with PaFog, also in PaStra prognostic equations are solved for the total number concentration $N_{c}$ and the total cloud water mixing ratio $q_{c}$,

$$
\begin{aligned}
\frac{\partial N_{c}}{\partial t} & =\frac{\partial}{\partial z}\left(k_{h} \frac{\partial N_{c}}{\partial z}\right)-\left\{w+w_{t, c}\right\} \frac{\partial N_{c}}{\partial z}+S\left(N_{c}\right), \\
\frac{\partial q_{c}}{\partial t} & =\frac{\partial}{\partial z}\left(k_{h} \frac{\partial q_{c}}{\partial z}\right)-\left\{w+w_{t, c}\right\} \frac{\partial q_{c}}{\partial z}-\left(\frac{\partial q_{c}}{\partial t}\right)_{d f}+\frac{C_{c}}{\rho} .
\end{aligned}
$$

Here, $w_{t, c}$ is the terminal velocity of the falling cloud droplets and $S\left(N_{c}\right)$ is a source term for cloud droplets in case of activation. This term is calculated by means of the Twomey relation (Twomey 1959). According to Nickerson et al. (1986), the cloud-droplet number concentration $N_{c}$ is assumed to be given by a lognormal size distribution. The term $\left(\partial q_{c} / \partial t\right)_{d f}$ occurring in Eq. $3 \mathrm{~b}$ has been newly introduced in PaStra. It describes the loss of cloud water due to drizzle water formation and is simply given by

$$
\begin{aligned}
\left(\frac{\partial q_{c}}{\partial t}\right)_{d f} & =\alpha q_{c}, \\
\alpha & =\frac{q_{c}}{q_{c, \text { crit }}} \frac{1}{3600},
\end{aligned}
$$

where $\alpha$ has units of $\mathrm{s}^{-1}$ and $q_{c, \text { crit }}=0.5 \mathrm{~g} \mathrm{~kg}^{-1}$. In the case of supersaturation, the condensation rate $C_{c}$ occurring in Eq. $3 \mathrm{~b}$ is given by $C$, cf. Eq. 1 . Hence, in PaStra the condensational growth of drizzle particles is neglected. This approximation takes into account that with increasing radius of the cloud droplets their diffusional growth becomes more and more inefficient. If evaporation occurs in subsaturated air, in agreement with the numerical results of MiStra, the total evaporation rate is partitioned between drizzle and cloud water. However, owing to the large fall speeds of the large drizzle particles, it is assumed that in a layer of $20 \mathrm{~m}$ vertical thickness not more than $15 \%$ of the entire drizzle water mass may evaporate. The prognostic equation for the drizzle water content, $q_{d}$, thus reads 


$$
\frac{\partial q_{d}}{\partial t}=\frac{\partial}{\partial z}\left(k_{h} \frac{\partial q_{d}}{\partial z}\right)-\left\{w+w_{t, d}\right\} \frac{\partial q_{d}}{\partial z}+\left(\frac{\partial q_{c}}{\partial t}\right)_{d f}+\frac{C_{d}}{\rho},
$$

where $C_{d}=C-C_{c}$ so that $C_{d}=0$ if condensation takes place and $C_{d}<0$ in the case of evaporation. Finally, for the calculation of the terminal fall speed $w_{t, d}$ of the drizzle particles it is assumed that they have a radius of $80 \mu \mathrm{m}$. In PaStra, all empirical parameters of the drizzle parametrization have been chosen in such a way that the model results resemble those of MiStra as closely as possible. However, a presentation of detailed sensitivity studies regarding the choice of these parameters is beyond the scope of the present paper. In summary, in PaStra the two-moment approach of PaFog for the cloud droplets has been extended by a one-moment scheme for the drizzle water content. Certainly, the present drizzle parametrization is a rather crude approach, however, as will be shown in Sect. 4, even with this simple parametrization the model results obtained with PaStra are clearly superior to those where drizzle formation is ignored.

\section{Numerical Results}

In this section results of numerical sensitivity studies with MiStra and PaStra are presented. The major focus of our investigations is on the impact of the complexity of the two cloud schemes on the model results. With the present approach, this task may be easily realized since we are able to switch between simulations with the detailed spectral microphysics scheme (MiStra) and the numerically efficient two-moment parametrization (PaStra), thereby leaving the model dynamics unchanged. The present study deals with the time evolution of the cloudtopped MBL, and in order to facilitate the comparison between both models, the initial state of the atmosphere has been chosen in such a way that a quasi-steady state of the cloud-topped MBL evolves.

The numerical simulations have been carried out by using, within the PBL, a vertically stretching grid mesh where the first layer above the Earth's surface has a thickness of 1 $\mathrm{m}$. The thickness of the overlying layers increases by applying a constant stretching factor yielding grid distances of $7 \mathrm{~m}, 15 \mathrm{~m}$, and $30 \mathrm{~m}$ at $200 \mathrm{~m}$ (layer 68), $500 \mathrm{~m}$ (layer 95), and $1000 \mathrm{~m}$ height (layer 119), respectively. All prognostic equations are solved in the lowest $2500 \mathrm{~m}$ of the atmosphere (150 layers). For the calculation of the atmospheric radiative fluxes, above $2500 \mathrm{~m}$ height 10 layers with prescribed constant values of all thermodynamic variables are added reaching up to a height of $50 \mathrm{~km}$. The numerical integration timestep has been chosen to $10 \mathrm{~s}$. In the microphysical part of MiStra this timestep is very large since the condensation/evaporation of the particles is explicitly calculated by moving them on their Köhler curves. This movement, which takes place in $r$-direction of the $(a, r)$-particle space, is obtained by solving for each $\left(a_{i}\right)$-aerosol bin an advection equation where the Courant numbers are calculated as a function of the droplet growth velocity of the particle. Specifically on the stable part of the Köhler curves this yields extremely large Courant numbers with values exceeding \pm 1000 . The reason for these large Courant numbers is given by the fact that with changing relative humidity the nonactivated aerosol particles almost instantly achieve their new equilibrium positions on the stable part of the Köhler curve. To handle this problem, a semi-Lagrangian version of the fourth-order advection scheme of Bott (1989) is applied.

In all model runs, the simulation starts on October 15 (day 0) at 0600 UTC and ends after $60 \mathrm{~h}$ simulation time on October 17 (day 2) at 1800 UTC, whereby the local time agrees with UTC. The geographical latitude is $50^{\circ} \mathrm{N}$. Since the stratus is simulated in a marine environment, the lower boundary of the model is given by the (saturated) sea surface with 
constant temperature of $12{ }^{\circ} \mathrm{C}$. Below the inversion layer $z_{\text {inv }}$ of initially $900 \mathrm{~m}$, constant values of $\theta=12{ }^{\circ} \mathrm{C}$ and $q=6.9 \mathrm{~g} \mathrm{~kg}^{-1}$ are applied reflecting a well-mixed PBL. However, initially in each layer the value of the specific humidity is limited in such a way that the relative humidity does not exceed $95 \%$. This applies to the layers between $360 \mathrm{~m}$ and $z_{\text {inv }}$. The purpose of this treatment is to obtain a pre-cloud model tuning phase during which all variables can adapt to each other. With the present model configuration the pre-cloud phase lasts about $10 \mathrm{~h}$. Immediately at $z_{i n v}$ the temperature increases by $\delta T_{i n v}=9{ }^{\circ} \mathrm{C}$ and $q$ decreases to $q_{i n v}=2 \mathrm{~g} \mathrm{~kg}^{-1}$. Between $z_{i n v}$ and $2500 \mathrm{~m}$ height a lapse rate of $6.5^{\circ} \mathrm{C} \mathrm{km}^{-1}$ is assumed while the specific humidity remains constant at the value of $q_{i n v}$. The large-scale vertical subsidence $w$ varies linearly from $w_{i n v}=-4 \mathrm{~mm} \mathrm{~s}^{-1}$ above $z_{i n v}$ to zero at the sea surface. During the model simulations the vertical $w$-profile is held constant. Above $z_{\text {inv }}$, the initial horizontal wind profile is given by a vertically constant geostrophic wind in the $x$-direction with $u_{g}=5 \mathrm{~m} \mathrm{~s}^{-1}$, which also linearly decreases to zero at the sea surface.

In MiStra the initial maritime aerosol size distribution has been formulated as a superposition of three log-normal size distributions. The empirical coefficients occurring in this formula have been chosen in such a way that the enveloping curve yields an optimal fit of typical maritime aerosol size distributions as observed by Hoppel et al. (1990), see also Bott et al. (1996). It is well known that in the cloudy atmosphere the collision/coalescence process is an efficient sink for particles, e.g., for the formation of a single drizzle particle with radius $100 \mu \mathrm{m}$ the collision and coalescence of 1000 droplets with radius $10 \mu \mathrm{m}$ is necessary. Without the permanent supply of new aerosol particles, after a short time period the number of aerosol particles available to serve as cloud condensation nuclei would be so small that unrealistically high supersaturations would be necessary to activate the remaining interstitial aerosol particles. In order to avoid this situation, in the numerical simulations with MiStra an aerosol source has been introduced. The strength of this source is chosen in such a way that during the model simulation, within the PBL the total particle cocentration remains more or less at the initial level of about 200 particles $\mathrm{cm}^{-3}$. The aerosol source is confined to the lowest $10 \mathrm{~m}$ of the atmosphere. Since in PaStra no prognostic equation is solved for the total number concentration of the aerosol particles, this quantity is held constant throughout the model simulations.

\subsection{Results of the Microphysical Cloud Model}

In the following a particular layer will be denoted as a cloud layer if its cloud water content exceeds the threshold value of $0.01 \mathrm{~g} \mathrm{~kg}^{-1}$, irrespective of its drizzle water content. Figure $1 \mathrm{a}$ depicts a contour plot of the total liquid water content as a function of time (UTC) and height. The entire cloud region is located between the red lines at cloud top and cloud base. Moreover, the yellow line denotes the saturation level that divides the cloud into a supersaturated (above) and subsaturated (below) part. As can be clearly seen, stratus formation starts on day 0 at about 1630 UTC (henceforth 0:1630 UTC) at $500 \mathrm{~m}$ height. It takes roughly two hours until the cloud top has reached its final height of about $720 \mathrm{~m}$. In contrast to the cloud top, the cloud base shows slight diurnal variations between $280 \mathrm{~m}$ in the night and $330 \mathrm{~m}$ in the early afternoon. The figure also demonstrates that the cloud is supersaturated only in its upper third. Hence, in a simple cloud parametrization scheme it might be critical to treat only saturated layers as cloud layers. The maximum total water content never exceeds 0.5 $\mathrm{g} \mathrm{kg}^{-1}$ and is always increasing with height. Owing to the solar irradiation, the total water content is smaller during the day than during the night. As an example of this behaviour, Fig. $1 \mathrm{~b}$ shows vertical profiles of the total liquid water content at the times 1:0600 UTC, 1:1400 UTC, 2:0600 UTC, and 2:1400 UTC. 

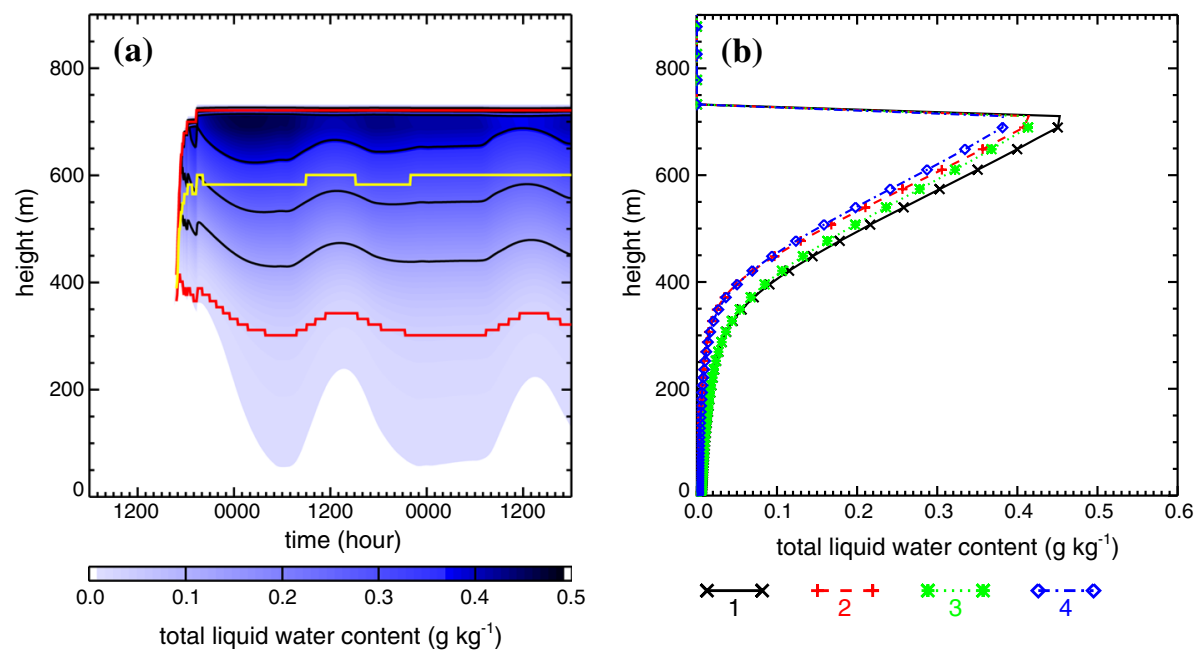

Fig. 1 a Total liquid water content as a function of time (UTC) and height for the MiStra model run. Red lines: cloud region, yellow line: saturation level. b Vertical profiles of the total liquid water content at the times 1:0600 UTC (curve 1), 1:1400 UTC (curve 2), 2:0600 UTC (curve 3), 2:1400 UTC (curve 4)
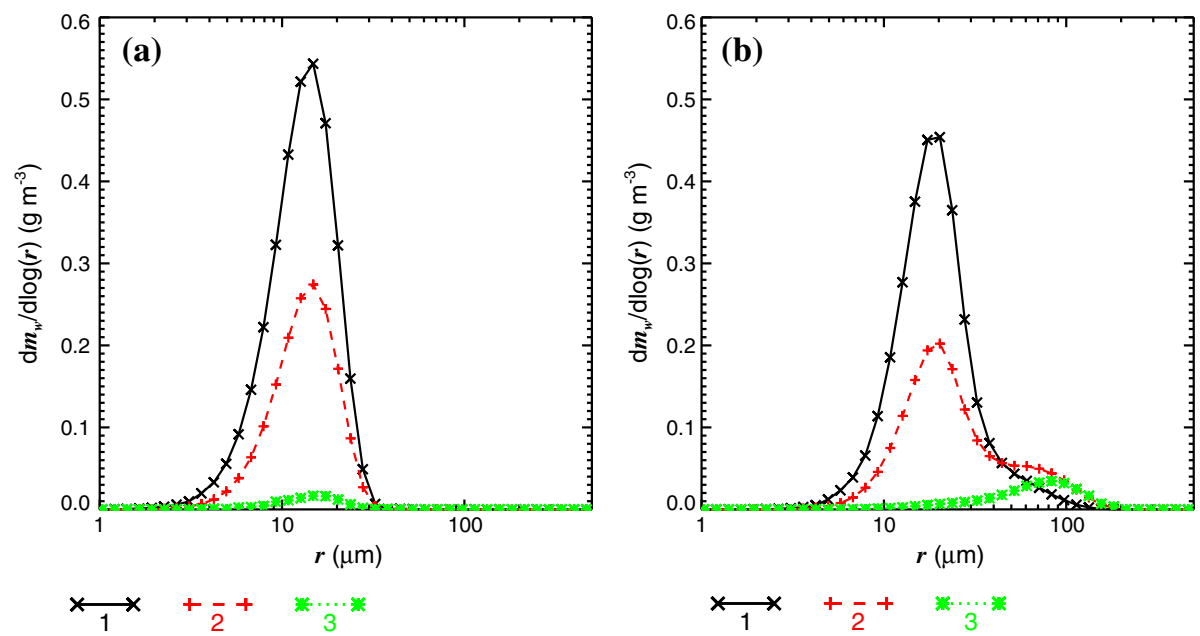

Fig. 2 Liquid water mass as a function of total particle radius at 2:0000 h. a MiStra without collision/coalescence. b MiStra control run. Curve 1: cloud top, curve 2: middle of the cloud, curve 3: cloud base

The justification for the above chosen values of the radii $\left(r_{1}, r_{2}\right)$ dividing the particle spectrum into aerosol particles, cloud droplets, and drizzle particles, follows from Fig. 2 depicting the spectral distribution of the total liquid water mass at the time 2:0000 UTC at cloud top (711 m, curve 1), in the middle of the cloud (523 m, curve 2), and at cloud base (307 m, curve 3). Curves taken at other model times yield similar results. Figure 2a shows the distributions from a simulation where collision/coalescence has been switched off, while Fig. $2 b$ denotes the results from the MiStra control run. It is clearly seen that in the model run without collision/coalescence the liquid water is mainly distributed over particles in the size 

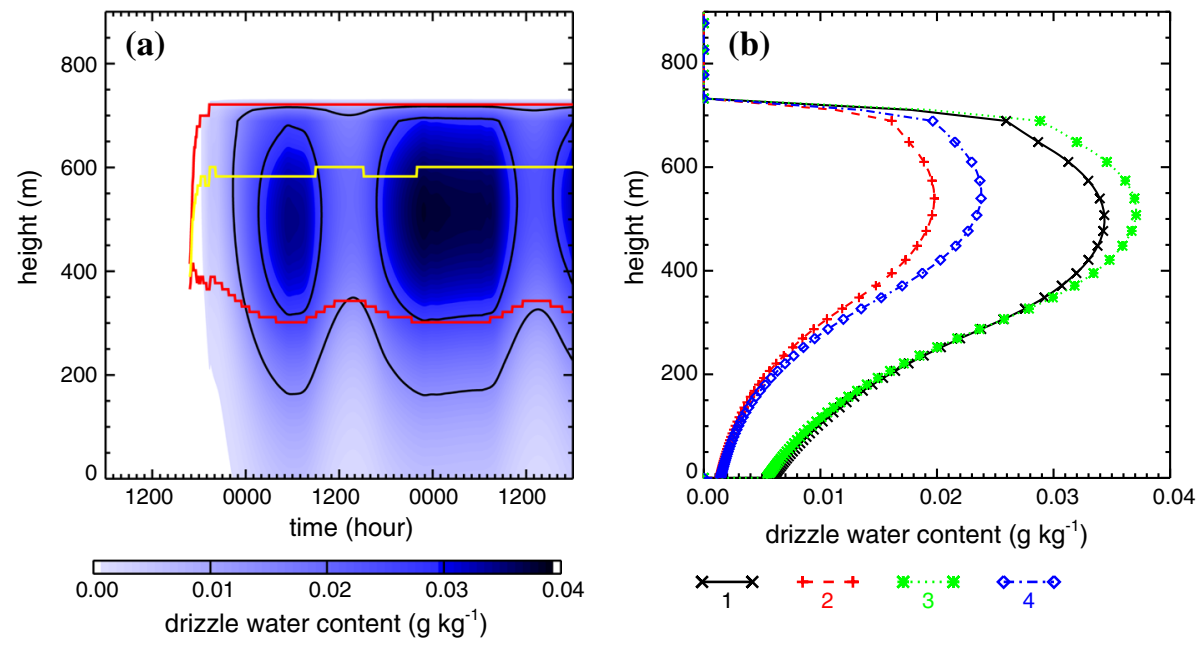

Fig. 3 a Drizzle water content as a function of time (UTC) and height for the MiStra model run. Red lines: cloud region, yellow line: saturation level. b Vertical profiles of the drizzle water content at the times indicated in Fig. 1

range 2-30 $\mu \mathrm{m}$. This size range consists of activated aerosol particles solely growing by the diffusional uptake of water vapour. In contrast to this, the results of the control run show the evolution of a bimodal structure of the liquid water distribution resulting from the diffusional growth and the collision/coalescence process that yields particles with radii exceeding 40 $\mu \mathrm{m}$. Hence, the model reflects the well-known fact that with increasing particle radius the diffusional growth of cloud droplets becomes more and more inefficient so that the major source of large drops is the collision/coalescence process, (see, e.g., Pruppacher and Klett 1997).

Figure 3 shows a contour plot of the drizzle water content (part a) and its vertical profiles (part b) at the times indicated in Fig. 1. In contrast to the total liquid water content, the maximum drizzle water content, which during the entire model simulation remains always below $0.035 \mathrm{~g} \mathrm{~kg}^{-1}$, is located in the middle of the cloud. The reason for this is that drizzle particles are mainly formed in the upper cloud layers, but owing to their size, they have relatively large fall speeds. The increasing evaporation in the lower cloud layers yields the observed local maxima of $q_{d}$ in the middle of the cloud. As was to be expected, during the day the drizzle water content is smaller than during the night. Drizzle also appears between the sea surface and cloud base. However, the resulting accumulated precipitation rate at the sea surface amounts only to $0.01 \mathrm{~mm}$ at 1:0000 UTC, $0.32 \mathrm{~mm}$ at 2:0000 UTC, and $0.54 \mathrm{~mm}$ at 2:1800 UTC.

Another striking feature of Fig. 3 is given by the fact that drizzle formation is stronger during the second day than during the first day, (compare curves 1 with 3 and 2 with 4 ). This is explained by the fact that after cloud formation, drizzle particles are permanently produced so that their number concentration is increasing with time, thus improving the collection efficiency.

From the contour plots of the total liquid water and the drizzle water content (Figs. 1a, 3a) it is concluded that shortly after its formation the stratiform cloud achieves a quasi-steady state with constant cloud top and only slightly varying cloud base. Also the total liquid water content is diurnally varying with minimum and maximum values during the day and night, 
respectively. The quasi-steady behaviour of the stratus is not restricted to the cloud itself, but it is also observed in the time evolution of all other thermodynamic variables describing the cloud-topped MBL (not shown). This finding is not surprising, in fact it is an expected feature of the simulated boundary layer. The reason for this is that the external forcing terms driving the MBL, i.e. surface heat and moisture fluxes as well as large-scale subsidence, are held constant throughout the model simulations. Only the insolation is a diurnally varying external forcing term yielding the observed diurnal fluctuations of the stratus in terms of its cloud-base height and the total liquid water content.

Hence, it may also be expected that the quasi-steady state of the cloud is expressed by nearly vanishing local time rates of change of all prognostic variables. That this is indeed the case is clearly demonstrated in Fig. 4 showing vertical profiles of the tendencies of the temperature, the specific humidity, the cloud and the drizzle water content at model time 2:0000 UTC. In addition to the total tendencies (curves 1), the figure also depicts for each variable the tendencies that result from different physical processes occurring in the corresponding prognostic equations. A common feature of the four figure panels is given by the fact that all total tendencies are several orders of magnitude smaller than the tendencies of the different single physical processes. This reflects the evolution of a quasi-steady state of the boundary layer and demonstrates that during the evolution of the cloud a fine balance is established between the different contributions to the total tendencies even though some of them achieve considerably large values. Corresponding vertical profiles of the tendencies taken at other model times show similar behaviour.

Figure 4a depicts the temperature tendencies and demonstrates that at cloud top strong warming occurs due to the condensation process and the associated release of latent heat. The peak value amounts to $24{ }^{\circ} \mathrm{C}$ per hour. These extremely large heating rates are almost completely balanced by turbulent mixing (curve 3 ) and radiative cooling (curve 5). Owing to the well-mixed state of the PBL, large-scale subsidence plays only a minor role for the temperature balance yielding slight warming rates at the inversion layer. Below the saturation level at $600 \mathrm{~m}$ height (see Fig. 1) evaporative cooling takes place, which is almost completely balanced by turbulent mixing. From Fig. $4 \mathrm{~b}$ it is seen that the tendencies of the specific humidity show the expected behaviour, that is strong decrease (increase) above (below) the saturation level as caused by condensation (evaporation). These tendencies are almost completely balanced by those of turbulent mixing. Again, large-scale subsidence is of minor importance yielding at cloud top a decrease of the specific humidity due to the subsidence of dry air aloft.

Similarly, the cloud water tendencies (Fig. 4c) are mainly characterized by a balance of condensation/evaporation and turbulent mixing. However, curve 2, which now in addition to the large-scale subsidence also includes the gravitational settling of the cloud droplets, has a strong negative peak in the uppermost cloud layer. The tendency of the cloud droplets loss due to collision/coalescence (curve 5) is relatively small with minimum values in the upper cloud region. Finally, from the tendencies of the drizzle water content (Fig. 4d) it is concluded that, owing to the large fall speed of the drizzle particles, their gravitational settling plays a dominant role yielding a pronounced decrease at cloud top and an increase at cloud base and below. This explains the typical shape of the verticle drizzle water profiles shown in Fig. 3. The gravitational settling tendency is balanced by turbulent mixing (curve 3) and the production rate by collision/coalescence (curve 5). Moreover, the tendency curve 4 shows a very slight increase at cloud top by condensation, but below $400 \mathrm{~m}$ a distinct decrease by evaporation of drizzle particles. Note the different scales of the abscissa for the drizzle tendencies in comparison to those of the cloud water and the specific humidity. 

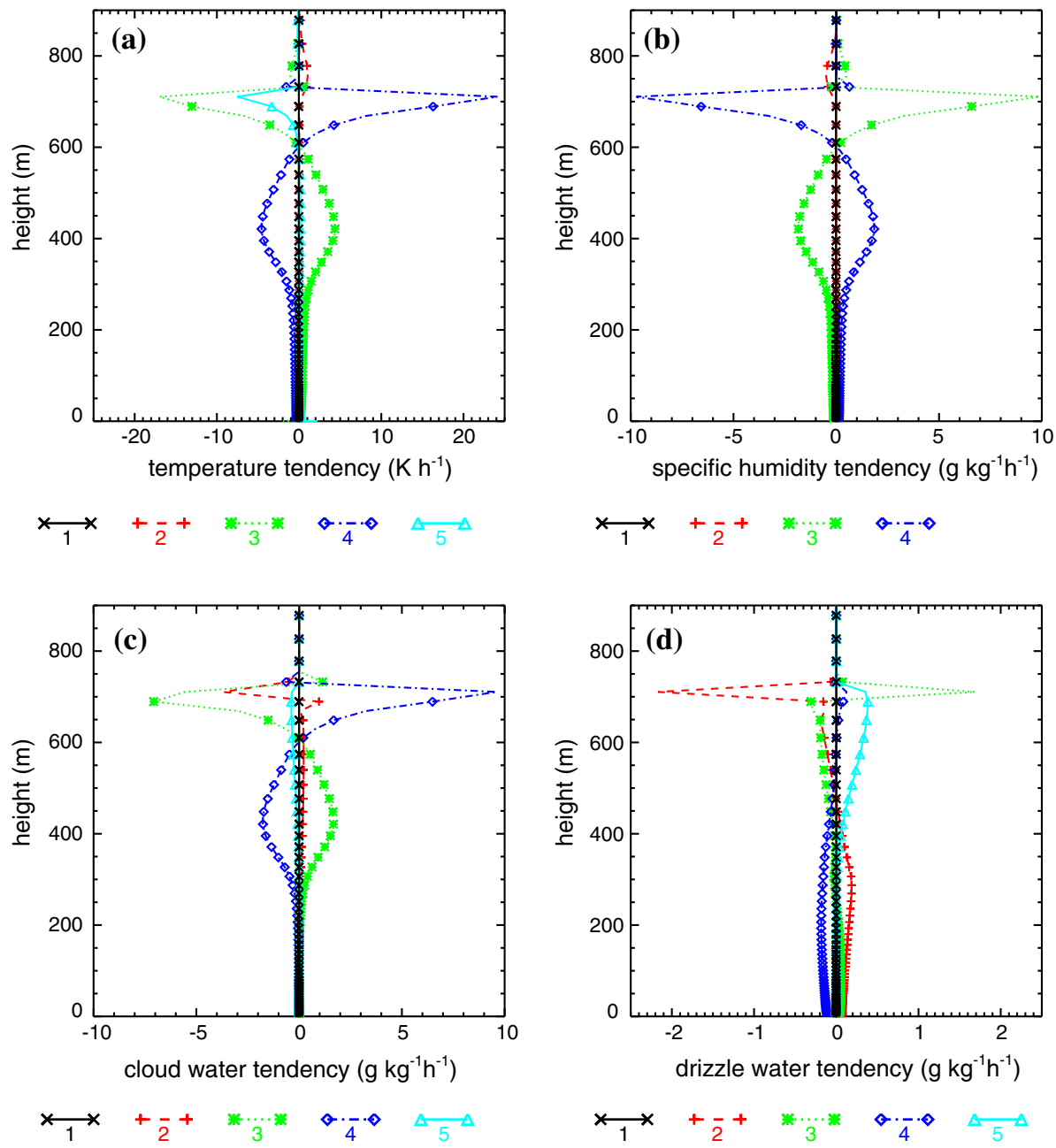

Fig. 4 Tendencies of a temperature, b specific humidity, $\mathbf{c}$ cloud water, and d drizzle water at 2:0000 UTC for the MiStra model run. Curve 1: total tendency, curve 2: large-scale subsidence, curve 3: turbulence, curve 4: condensation/evaporation, curve 5a: radiative cooling, curves $5 \mathrm{c}$, d: collision/coalescence

A very notable feature of all tendency curves of MiStra (also those at all other times not shown) is the fact that they are characterized by a smooth shape. This holds in particular for the saturation level as well as the cloud base, i.e. no kinks or other discontinuities occur in all tendency curves. This behaviour is a direct consequence of the microphysical treatment of the particle spectrum in a joint distribution of unactivated aerosols, activated cloud droplets, and drizzle particles. In the following section it will be shown that for PaStra this behaviour is unfortunately no more given.

In all numerical simulations with MiStra or PaStra, the evolution of a quasi-steady state of the MBL is a typical feature that is caused by the constant or temporally barely varying external forcing terms. Numerous other sensitivity studies have been performed with different values of the major forcing terms, e.g., the sea-surface temperature or the strength of the large- 


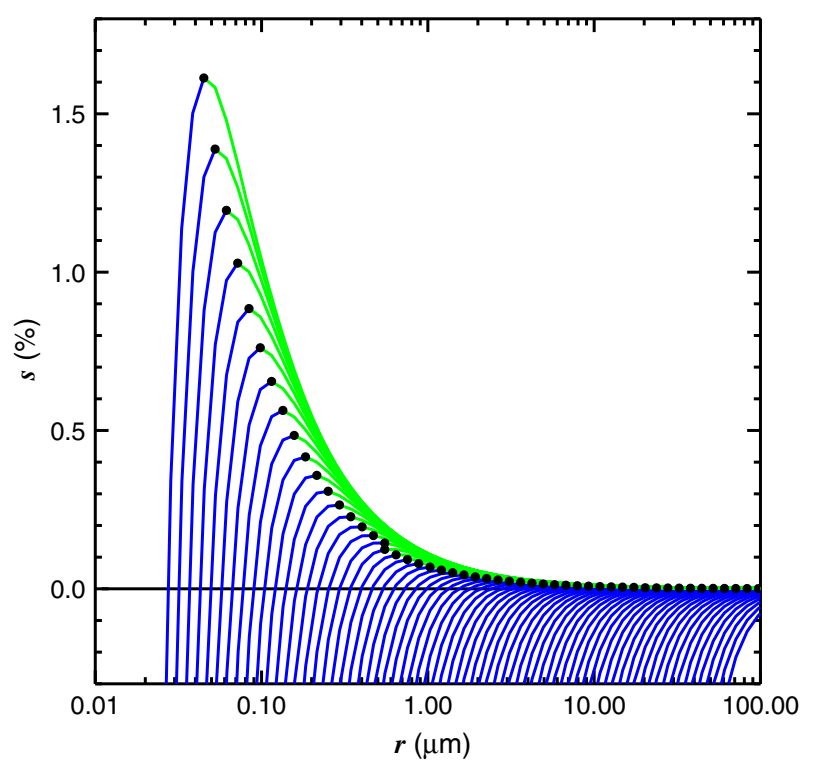

Fig. 5 Köhler curves of the 70 aerosol classes depicting the particle radius $r$ at a given supersaturation $s$. Blue: stable part, green: unstable part. Black dots: critical radius and supersaturation

scale subsidence. These studies yielded different stratiform clouds regarding for instance the vertical extent of the cloud or the liquid water content, but in all of these cases some time after cloud formation a quasi-steady state evolved. The sensitivity of the model with respect to the variation of different input parameters is not the subject of the present investigation.

The subdivision of the aerosol particle spectrum into 70 bins with radius $a_{i}, i=1, \ldots 70$ yields 70 different Köhler curves. The 70 curves of the present investigation are depicted in Fig. 5. For a given aerosol radius $a_{i}$ the Köhler curve consists of a stable (blue) and an unstable part (green), see, e.g., Pruppacher and Klett (1997). At the maximum of each curve (black dots) the particles leave the stable part and enter the unstable part of the Köhler curve. This happens if the supersaturation of the environment $s$ exceeds the critical value $s_{c r i t}\left(a_{i}\right)$ as given by the black dots. The total radius at the critical supersaturation is called the critical radius $r_{c r i t}\left(a_{i}\right)$. Once a particle has reached the unstable part of its Köhler curve, it continues to grow by diffusion of environmental water vapour as long as the relative humidity exceeds $100 \%$, i.e. $s>0$. However, with increasing total particle radius this diffusional growth becomes less efficient converging for large particles towards zero.

Figure 6 shows the positions of the particles in the two-dimensional $(a, r)$-particle space at model time 2:0000 UTC, (a) at cloud top (711 m), (b) in the middle of the cloud $(523 \mathrm{~m})$, and (c) at cloud base $(307 \mathrm{~m})$. The relative humidities in these layers are $100.7 \%, 99.8 \%$, and $97.3 \%$, respectively. During the entire simulation time and in all cloud layers the relative humidity never exceeds $100.8 \%$, i.e. $s$ always remains below $0.8 \%$. For each aerosol class $i$, the corresponding particle distribution, $f\left(a_{i}, r\right)$, is subdivided into four groups consisting of particles with values in the range $>99 \%$ (red), 50-99\% (green), 10-50\% (blue), and $<10 \%$ (cyan) of the maximum value of $f\left(a_{i}, r\right)$. Moreover, the black dots denote the value of the critical radius $r_{c r i t}\left(a_{i}\right)$ as obtained from the Köhler curves in Fig. 5. Hence, particles smaller (larger) than their critical radius are nonactivated aerosol particles (activated cloud droplets). It is clearly seen that, owing to $s<0.8 \%$ and in agreement with the Köhler curves, 

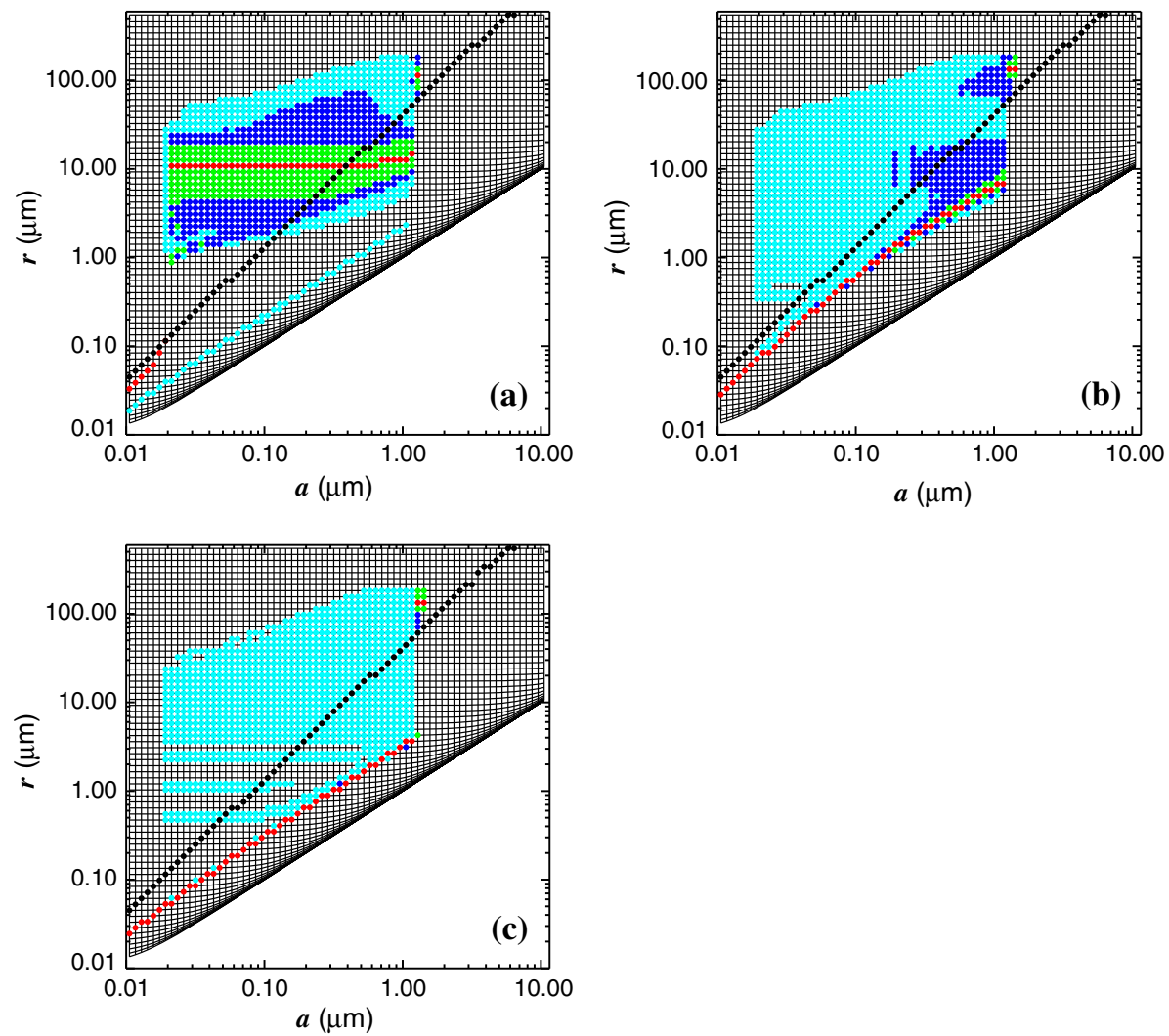

Fig. 6 Particle positions in the $(a, r)$-particle space at 2:0000 UTC. a Cloud top, b middle of the cloud, c cloud base. Red: $>0.99$, green: $0.5-0.99$, blue: $0.1-0.5$, cyan: $<0.1$, black: critical radii, see also text

in each cloud layer the smallest aerosol particles are never activated. This is expressed by the $f\left(a_{i}, r\right)$-distributions of the smallest aerosol particles having a total radius smaller than $r_{\text {crit }}\left(a_{i}\right)$. These are the interstitial aerosol particles.

At cloud top (Fig. 6a), in each $a_{i}$-aerosol class some very small particles occur as indicated by the lower line of cyan dots. These particles have just been entrained from aloft and are moving toward the equilibrium positions on their Köhler curve or they will be activated. All particles with dry aerosol radius $a_{i}>0.02 \mu \mathrm{m}$ are actived yielding their maximum-value positions (red dots) at $r \approx 10 \mu \mathrm{m}$ or larger. Recall that particles with total radius in the order of $10 \mu \mathrm{m}$ are cloud droplets as formed by diffusional growth, while particles with radius exceeding $40 \mu \mathrm{m}$ may be viewed as drizzle particles resulting from collision/coalescence processes. Finally, Fig. 6a shows that most of the large aerosol particles with $a_{i}>0.4$ $\mu \mathrm{m}$ are not activated even though the environmental supersaturation exceeds their critical supersaturation $s_{c r i t}\left(a_{i}\right)$. This is explained by the fact that, owing to the size of these particles, their diffusional growth velocities are so small that they may never reach their critical radius.

While at cloud top in most of the $\left(a_{i}\right)$-aerosol bins the particles have been activated, the opposite is the case in the middle of the cloud and particular at cloud base where the air is subsaturated. This is expressed by the locations of the red dots in the $(a, r)$-particle space, which are mainly found at $r$-values smaller than the critical radii (black dots), see Fig. 6b, c. In the subsaturated cloud regions, mainly the small cloud droplets evaporate while drizzle 
evaporation is less efficient. This behaviour has two causes: firstly, for a single particle the evaporation flux is proportional to its surface area. Secondly, within the cloud the integrated surface of all cloud droplets is distinctly larger than that of all drizzle particles, e.g., 1000 droplets of $r=10 \mu \mathrm{m}$ yield the same water mass as one drizzle particle of $r=100 \mu \mathrm{m}$, but a ten times larger integrated surface. Nonetheless, in all subsaturated cloud layers there always appear some large cloud droplets as indicated by the cyan dots in Fig. 6b, c. These are permamently brought down from higher cloud layers by turbulent mixing processes, see also the cloud water tendencies in Fig. 4.

Figure 7 depicts the two-dimensional water and aerosol mass distributions in the cloud layers shown in Fig. 6 . While the water mass $m_{w}$ of a single particle may be modified by condensation/evaporation and collision/coalescence, its aerosol mass $m_{a}$ will only change in the case of collision/coalescence with other particles. At cloud top, most of the liquid water is carried by the cloud droplets with $r<30 \mu \mathrm{m}$. In lower cloud layers, the cloud water content decreases while the drizzle water content becomes more and more dominant. At cloud base, the drizzle particles carry most of the liquid water. Note, however, the different scales of the colour bars in Fig. 7a, c, e. As was to be expected, in the supersaturated cloud regions a distinct fraction of aerosol mass is found in the size range of cloud droplets and drizzle particles while in the subsaturated cloud regions most of the aerosol mass appears in the size range of the small nonactivated particles. Note again the different scales of the colour bars in Fig. 7b, d, f.

The aerosol processing resulting from particle collision/coalescence is impressively demonstrated in Fig. 8 depicting spectral distributions of the aerosol mass at model initialization time (curve 1), 1:0000 UTC (curve 2), 1:1200 UTC (curve 3), and 2:0000 UTC (curve 4). Curves 2-4 are taken in the middle of the cloud at $523 \mathrm{~m}$ height. In the early stage of the cloud, collision/coalescence is not yet very efficient so that the main difference between curve 2 and the initial mass distribution (curve 1) is caused by the aerosol source term included in MiStra. Both curves have a bimodal form with maxima of the spectral aerosol mass at $a=0.08 \mu \mathrm{m}$ and $a=0.25 \mu \mathrm{m}$. With increasing age of the cloud, this bimodal structure is modified in such a way that the first maximum distinctly decreases while at the same time the second maximum increases thereby shifting from $a=0.25 \mu \mathrm{m}$ to $a=0.5$ $\mu \mathrm{m}$. The bimodal aerosol mass distributions calculated with MiStra resemble those typically observed in the marine environment (see, e.g., Hoppel et al. 1990).

\subsection{Results of the Parametrized Cloud Model}

In the following, model results will be presented where, in the numerical simulations, the microphysical module MiStra has been replaced by PaStra. Recall that all other modules, such as the model dynamics, the turbulence and the radiation scheme remain unchanged. Figure 9 depicts a contour plot of the total liquid water content as a function of time (UTC) and height and its vertical profiles at the same times as in Fig. 1. By comparing both figures, at first glance PaStra and MiStra yield a similar spatio-temporal evolution of the stratus. This holds for the time of cloud formation, the cloud-top height as well as the diurnal variation of the cloud base being in PaStra somewhat more pronounced than in MiStra. Also, the total liquid water content is in both model configurations quite similar whereby PaStra yields slightly larger values, particularly on day 2 (see the vertical profiles in Figs. 1b, 9b). Finally, the contour plot and the vertical profiles of the drizzle water content as depicted in Fig. 10 support this first impression of a quite similar behaviour of both cloud microphysical schemes. 

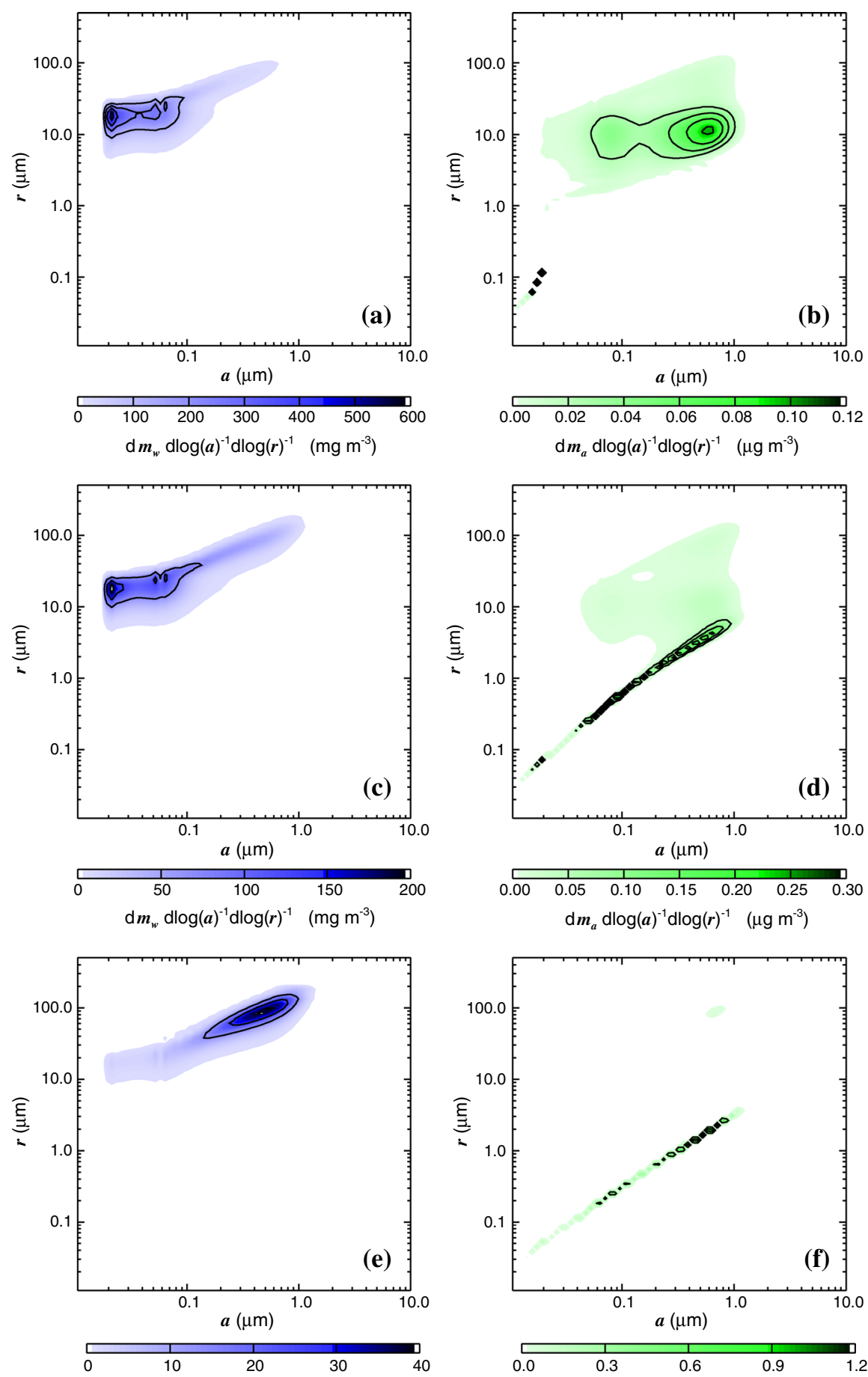

$\mathrm{d} \boldsymbol{m}_{w} \operatorname{dlog}(a)^{-1} \operatorname{dlog}(r)^{-1} \quad\left(\mathrm{mg} \mathrm{m}^{-3}\right)$

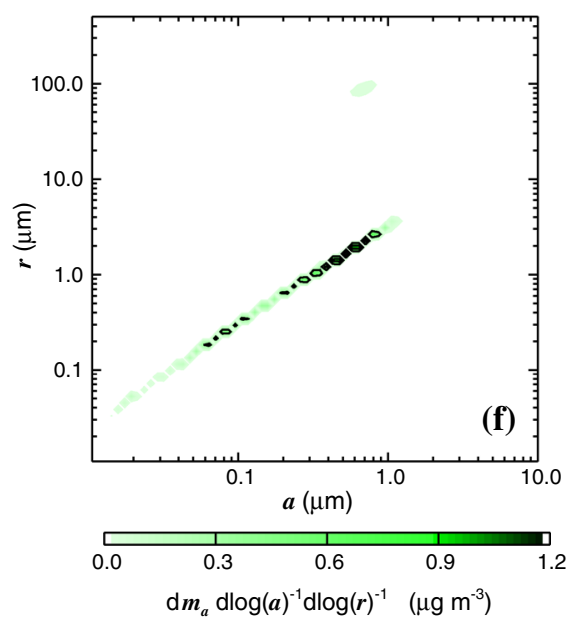

Fig. 7 Liquid water (left) and aerosol mass distributions (right) in the (a,r)-particle space at 2:0000 UTC. Cloud top $(\mathbf{a}, \mathbf{b})$, middle of the cloud $(\mathbf{c}, \mathbf{d})$, cloud base $(\mathbf{e}, \mathbf{f})$ 


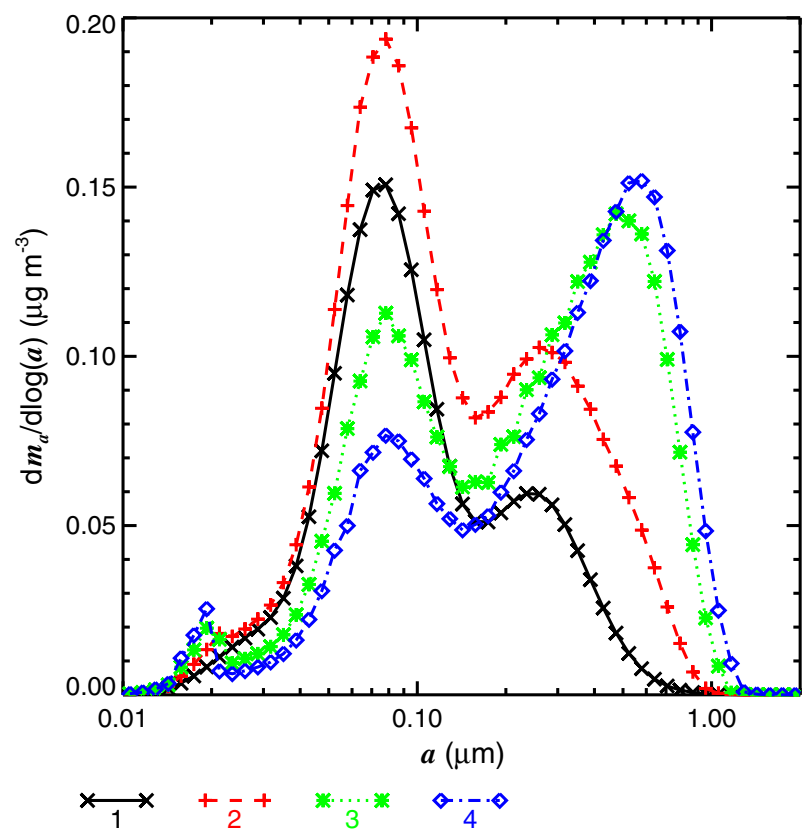

Fig. 8 Spectral distribution of the aerosol mass at 0:0600 UTC (curve 1), 1:0000 UTC (curve 2), 1:1200 UTC (curve 3), and 2:0000 UTC (curve 4)
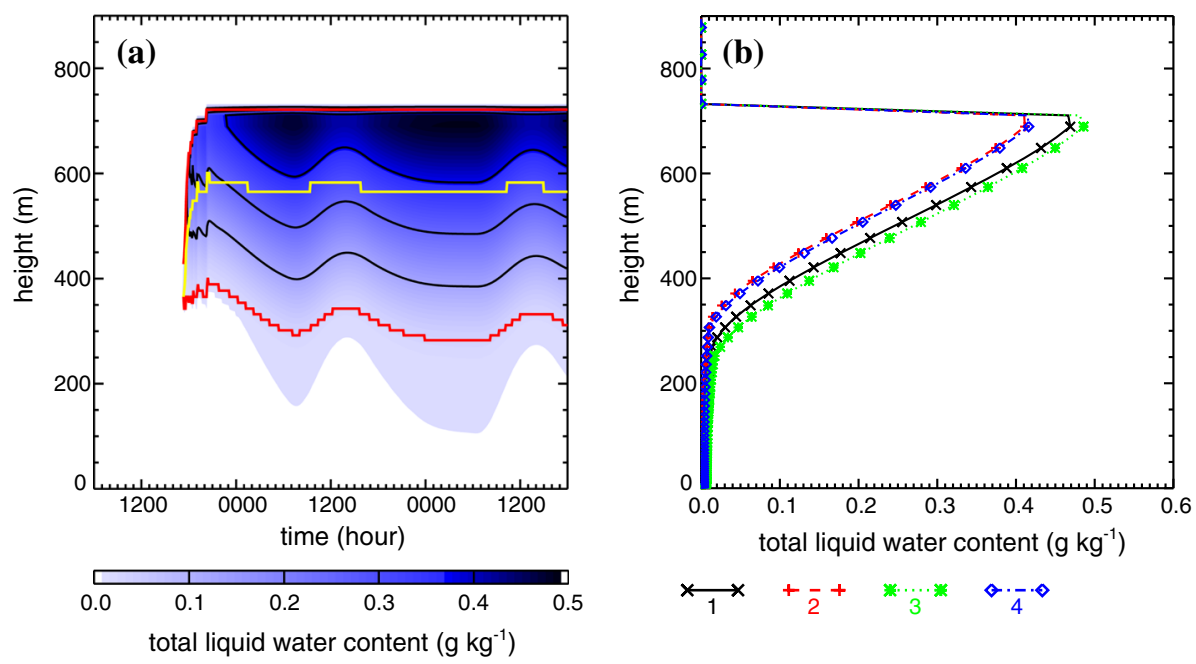

Fig. 9 a Total liquid water content as a function of time (UTC) and height for the PaStra model run. Red lines: cloud region, yellow line: saturation level. b Vertical profiles of the total liquid water content at the times indicated in Fig. 1

Figure 11 shows vertical profiles of the tendencies of temperature, specific humidity, cloud and drizzle water content analogous to those of MiStra as presented in Fig. 4. One can see that also in PaStra a quasi-steady state with minuscule total tendencies is achieved. As was to be expected, for each variable and in each layer the balance is maintained in such a way that the 

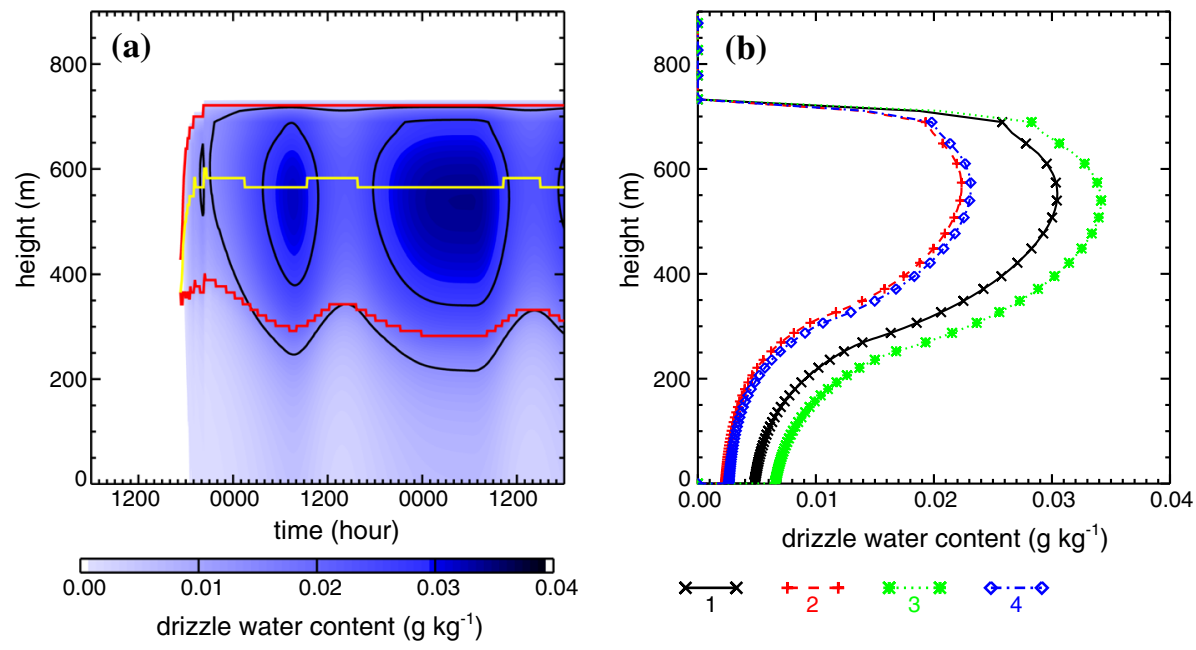

Fig. 10 a Drizzle water content as a function of time (UTC) and height for the PaStra model run. Red lines: cloud region, yellow line: saturation level. b Vertical profiles of the drizzle water content at the times indicated in Fig. 1

compensating physical processes have the same importance as in MiStra, e.g., at cloud top the latent heat release is primarily compensated by turbulent mixing and radiative cooling. However, by comparing for both cloud schemes the contributions of the different physical processes to the total tendencies, some distinct differences become obvious. This holds in particular for the condensation/evaporation process which in PaStra is clearly less pronounced than in MiStra, compare curves 4 in Figs. 4 and 11. At cloud top, condensation yields a tendency of the specific humidity of $-8 \mathrm{~g} \mathrm{~kg}^{-1} \mathrm{~h}^{-1}$ in PaStra and almost $-10 \mathrm{~g} \mathrm{~kg}^{-1} \mathrm{~h}^{-1}$ in MiStra, see curves 4 in Figs. $4 \mathrm{~b}$ and 11b. The corresponding latent heating rates differ in both models up to $4{ }^{\circ} \mathrm{C} \mathrm{h}^{-1}$. In PaStra, the maximum evaporation rate is observed close to cloud base; in MiStra it is located in higher cloud regions.

By recalling that in PaStra larger values of the total liquid water content are obtained than in MiStra (compare Figs. 1, 9), these results appear somehow surprising. Of course, the observed differences may be clearly attributed to the different treatment of cloud processes in both schemes. In MiStra the diffusional growth of the particles and their corresponding movement on the Köhler curves are explicitly calculated. Integrating the modified particle spectrum over the particle size range yields the condensation and evaporation rates. In PaStra, by contrast, simple empirical parametrization algorithms are utilized, such as the Twomey relation and others. Moreover, in MiStra the gravitational settling of each particle is calculated as a function of its mass, whereas in PaStra all cloud droplets fall with the same terminal velocity being calculated as a function of the mean particle radius. Finally, drizzle formation in MiStra is calculated by solving the stochastic collection equation, in PaStra a crude parametrization for drizzle formation is applied, see Eq. 4a.

In addition to the cloud water tendencies, also those of the drizzle water differ in both cloud schemes. While in MiStra a slight drizzle condensation rate occurs at cloud top, this process is ignored in PaStra. The largest differences in the tendency curves of drizzle water are observed below the saturation level of the clouds (MiStra: 600 m, PaStra: 565 m). In MiStra, drizzle evaporation is smoothly increasing between the saturation level and $200 \mathrm{~m}$ height and then slightly decreasing towards the ground. In contrast to this, in PaStra a noticeable drizzle 

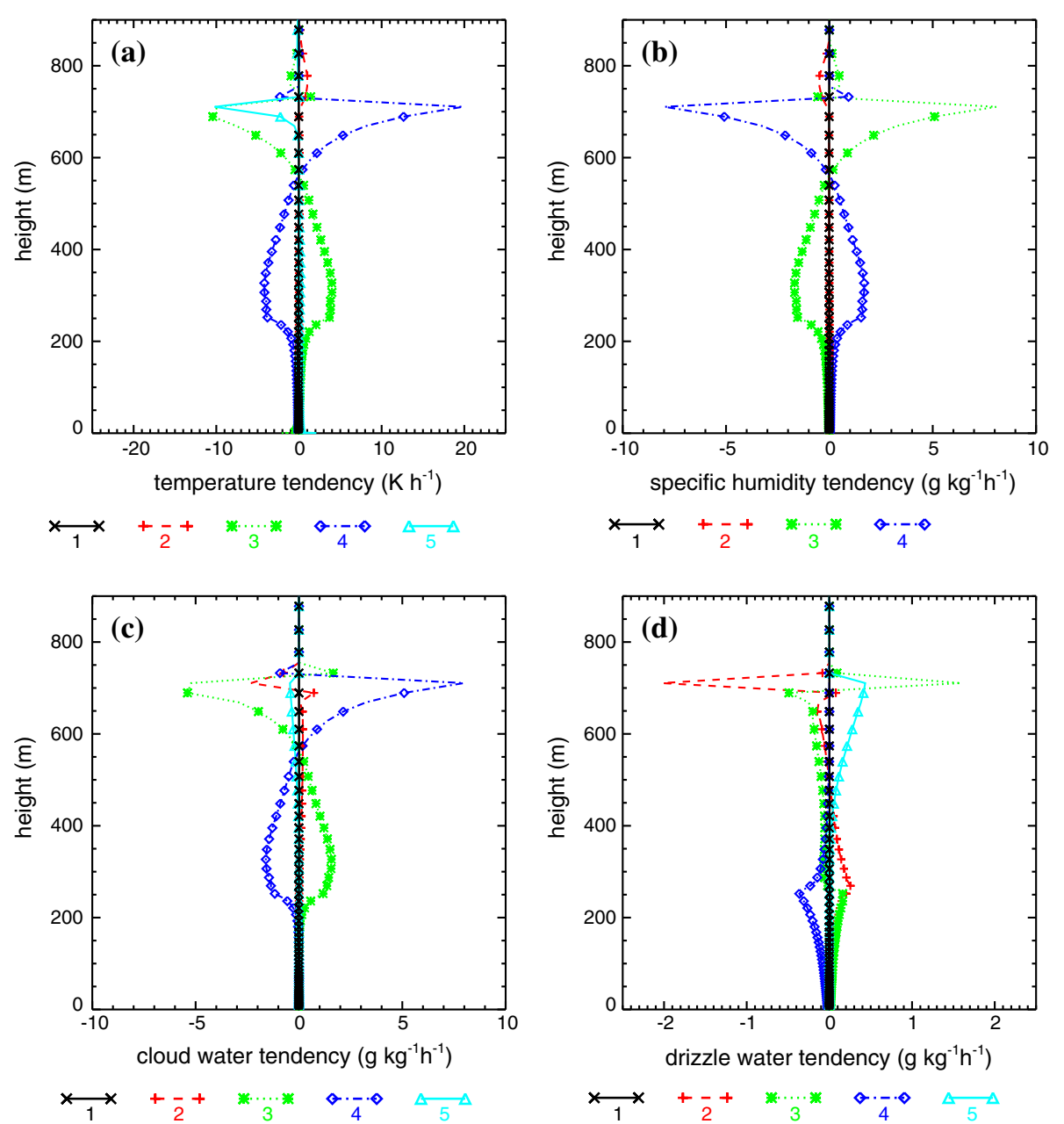

Fig. 11 Same as Fig. 4, but for the PaStra simulation

evaporation starts at first close to the cloud base and increases strongly until in $250 \mathrm{~m}$ height the evaporation rate is largest. Below this height, the evaporation rate is distinctly decreasing towards the ground. This behaviour is explained by the relatively simple parametrization of drizzle evaporation in PaStra. Firstly, it is assumed that only $15 \%$ of drizzle can evaporate in a 20-m thick layer, herewith roughly accounting for the high fall speeds of these large particles. Secondly, below the cloud base the calculated drizzle evaporation rate must be limited by the availability of drizzle water. Above $250 \mathrm{~m}$ height, this limitation is not in effect, however, below this height the calculated evaporation rate is always larger than the available drizzle water resulting in an effective evaporation rate that is clearly decreasing with decreasing height. As a consequence of this, in all tendency curves of PaStra some more or less pronounced discontinuities are observed at $250 \mathrm{~m}$ height.

Several sensitivity studies have been performed with PaStra where different values of the empirical model parameters have been tested (not shown). However, with these simulations it was not possible to obtain results that are an improvement on those presented here. 
Inaccuracies in the description of cloud microphysical processes are, of course, an inevitable consequence of the simple parametrizations of the different cloud processes as used in PaStra.

In summary, the comparison of the tendency curves of MiStra and PaStra demonstrates that PaStra behaves physically meaningful yielding acceptable results. However, it also reveals the deficiencies of the simple parametrization approaches implemented in PaStra. Nonetheless, it is important to include all relevant cloud microphysical processes, even in the present crude approach like the one-moment scheme for drizzle. This becomes very evident if in sensitivity studies some of these processes are ignored in the model simulations. Corresponding results will be shown in the following section.

\subsection{Ignoring Cloud Microphysical Processes}

The most important cloud microphysical processes of the present investigation of the cloudtopped MBL are given by condensation/evaporation, collision/coalescence and gravitational settling of the cloud droplets and drizzle particles. In fact, it turns out that only the interaction of these three processes yields the quasi-stationary behaviour of the stratus described above. This holds for the MiStra and likewise for the PaStra simulations. In this section, numerical sensitivity studies of MiStra and PaStra will be presented where in one simulation collision/coalescence as well as the gravitational settling of the particles are ignored while in another model run only collision/coalescence processes are neglected. Certainly, the first of these case studies, which considers only condensation/evaporation processes, yields the most simple approach to parametrize stratiform clouds.

Figure 12 depicts the results of the four model runs. In Fig. 12a, b, the simulations are shown where collision/coalescence together with particle sedimentation have been ignored, in Fig. 12c, d, only collision/coalescence processes have been switched off. Left (right) panels denote MiStra (PaStra) model runs. A common feature of all contour plots is given by the nonstationary behaviour of the cloud as expressed by the continuously vertical increase of the cloud top. Ignoring collision/coalescence and gravitational settling of the particles yields the largest effects, as expressed by a relatively fast increase of the cloud top and also distinctly lower liquid water contents than in the control runs. In the MiStra run, the cloud even disapears completely between 2:1100 UTC and 2:1400 UTC. Ignoring only collision/coalescence processes yields for MiStra and PaStra larger values of the total liquid water content than in the corresponding control runs (Figs. 1, 9). Furthermore, the vertical extent of the clouds is larger than in the upper panels of the figure. Finally, it is also seen that in both PaStra runs the cloud top increases slower whereas the cloud base is lower than in the MiStra runs.

The non-stationarity of the simulated stratus clouds may also be demonstrated by investigating the time evolution of the tendencies of the temperature and the specific humidity. Of particular importance are the tendencies as calculated in the first layer immediately above cloud top. The corresponding curves are shown in Fig. 13. Here, curves 1 denote the control runs of MiStra (panels a, c) and PaStra (panels b, d), curves 2 describe the model runs ignoring only collision/coalescene while curves 3 are the model configurations where both collision/coalescence and gravitational settling have been switched off. Note that with each vertical increase of the cloud top in discrete steps as given by the vertical model grid, also the first layer above the cloud is replaced by the next layer aloft.

The most striking feature of Fig. 13 is given by the fact that some time after cloud formation, in the control runs (curves 1 ) the tendencies are very small varying only slightly above and below the blue dashed zero line. On the contrary, in the other model runs the temperature 

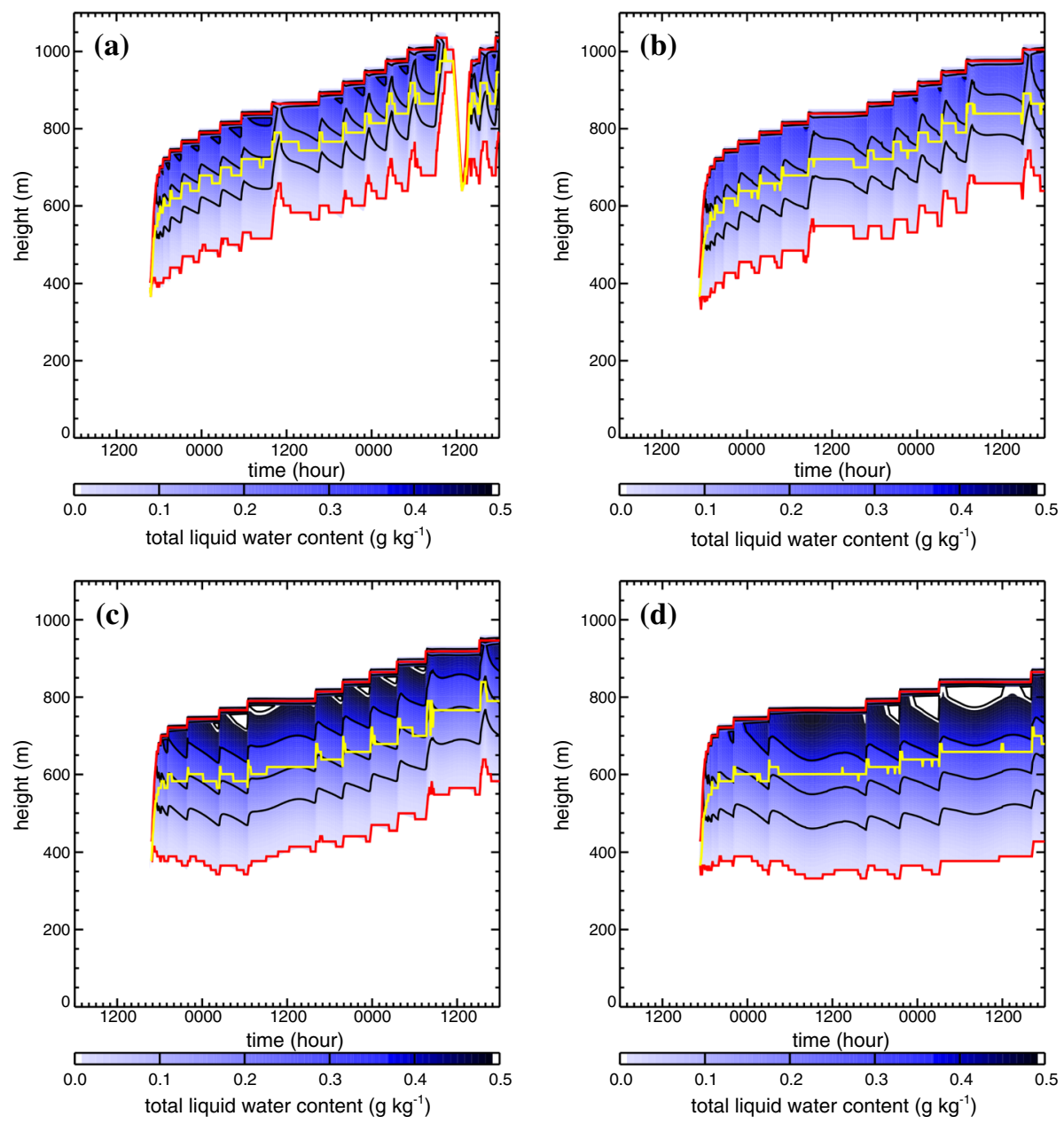

Fig. 12 Contour plots of the total liquid water content. a b No collision/coalescence and no sedimentation, c, d: no collision/coalescence. Left panels: MiStra model run, right panels: PaStra model run

tendencies are almost always negative and the specific humidity tendencies positive. Hence, the first layer above cloud top is permanently cooled and humidified, thus fostering the vertical increase of the cloud. Besides, the strong peaks occurring in the tendency curves of the figure result from the vertical increase of the cloud in discrete steps of the vertical model grid.

\section{Summary and Concluding Remarks}

The spectral microphysics cloud scheme MiStra has been compared with the two-moment cloud parametrization scheme PaStra. For this, both approaches have been embedded in a one-dimensional single-column model of the PBL describing cloud microphysical processes in a cloud-topped marine environment. MiStra treats in great detail the interaction 

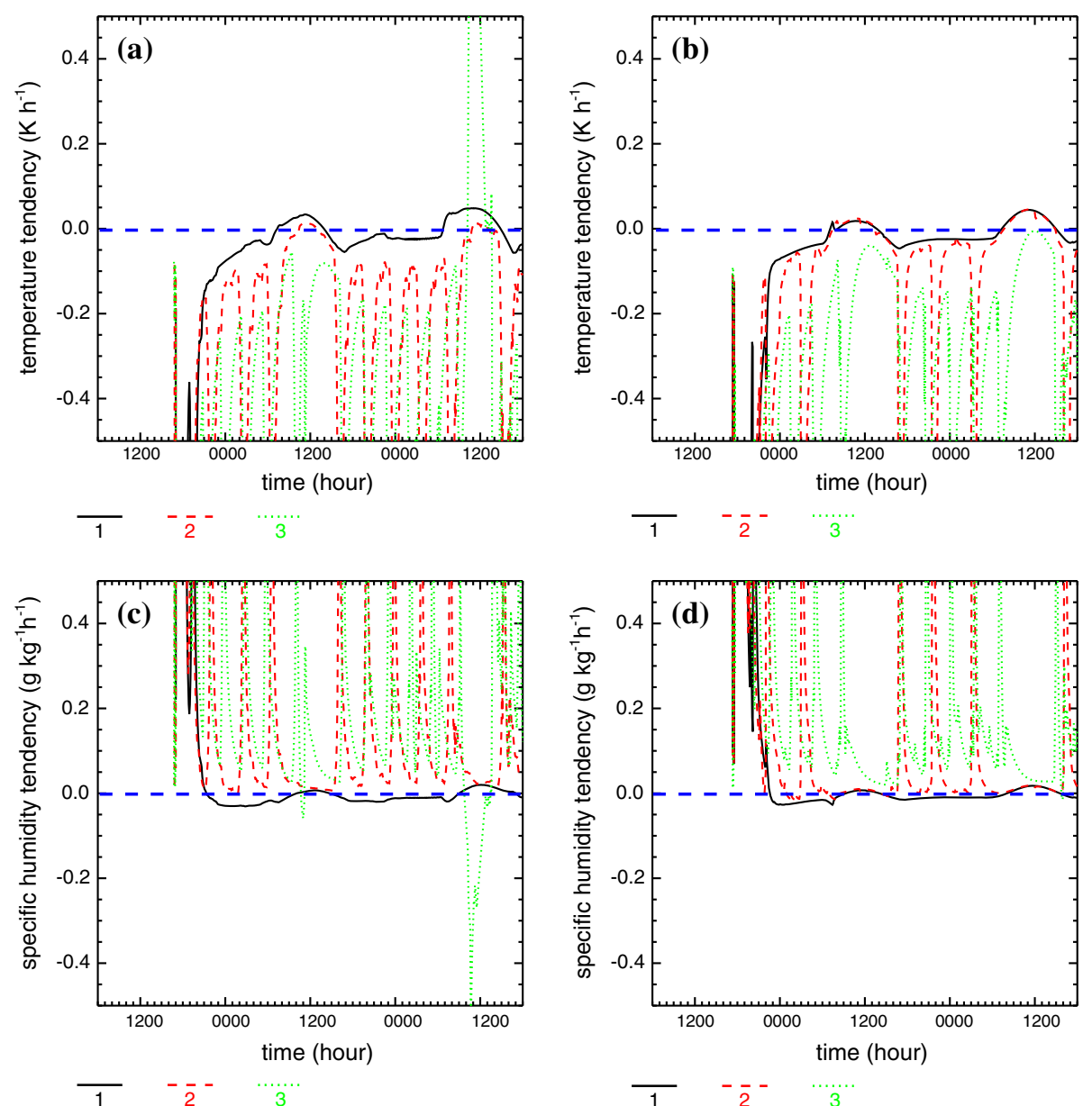

Fig. 13 Total tendencies immediately above cloud top as function of time (UTC). a, b Temperature, c, d specific humidity. curves 1: control run, curves 2: no collision/coalescence, curves 3: no collision/coalescence and no sedimentation. a, c MiStra model run, b, d PaStra model run

of aerosols, cloud droplets, and drizzle particles. This is achieved by utilizing for all particles a joint two-dimensional particle size distribution with the aerosol and the water mass as independent variables. The aerosol and water mass spectra are subdivided into 70 bins yielding an aerosol/droplet spectrum consisting of 4900 different particles. For each of these 4900 particle bins, a prognostic equation is included in MiStra. The activation process of aerosol particles to form cloud droplets is explicitly calculated by solving in each of the 70 aerosol size classes the corresponding droplet growth equation. Moreover, an extension of the stochastic collection equation for use in a two-dimensional particle space is utilized so that collision/coalescence processes can also be accounted for.

In the cloud parametrization scheme PaStra, a numerically very efficient treatment of cloud processes is applied so that this approach, contrary to MiStra, may also be used in threedimensional atmospheric models. The numerical efficiency of PaStra can only be achieved by a drastic simplification of the considered cloud microphysical processes. This results 
in a two-moment scheme for cloud droplets and the cloud water content combined with a one-moment scheme for the drizzle water content.

Since in MiStra all cloud processes are explicitly simulated, there are no empirical model parameters available that might be used to tune the model. In PaStra, on the contrary, several empirical parameters have been introduced in order to describe the cloud processes in an approximate, but numerically very efficient way. These empirical parameters have been chosen in such a way that the best agreement of the PaStra results with those of MiStra was obtained.

Numerical sensitivity studies have been performed with MiStra and PaStra showing that in both model configurations the cloud-topped MBL achieves a quasi-steady state. This behaviour is a consequence of the more or less constant values of the external forcing terms of the MBL, i.e. constant heat and moisture fluxes at the sea surface as well as a constant large-scale subsidence being assumed in the model runs. Hence, in the numerical simulations only the insolation is a diurnally varying external forcing term. The quasi-steady state of the stratiform cloud is well reflected by nearly vanishing tendencies of all prognostic model variables. A detailed analysis of these tendencies reveals that during the quasi-steady state of the cloud a fine balance is established between the contributions of the different physical processes to the total tendency of a particular prognostic variable whereby these single contributions may be considerably high.

A detailed description is presented of the spectral microphysical processes as calculated with MiStra. Here it is seen that the model is capable of simulating in great detail the activation process of aerosol particles as well as the diffusional growth of the activated cloud droplets. Collision/coalescence processes yield the formation of drizzle particles. The corresponding spectral aerosol mass distributions exhibit a bimodal form resembling those of typically observed aerosol mass distributions in the marine environment.

The numerical simulations with PaStra demonstrate that with this simple parametrization scheme it is possible to obtain reasonable results regarding the overall characteristics of the cloud-topped MBL. The times of cloud formation, the heights of cloud top and cloud base, the cloud and drizzle water content as well as the evolution of a quasi-steady state of the stratus compare well with those of MiStra. However, a more detailed comparison of the model results reveals some distinct differences between both cloud schemes. This holds in particular for the major cloud microphysical processes condensation/evaporation, gravitational settling of cloud droplets, and drizzle formation. As a consequence of this, the contributions of the single physical processes to the total tendencies of the prognostic variables differ distinctly between PaStra and MiStra.

Numerical sensitivity studies are presented demonstrating that in MiStra as well as in PaStra all cloud microphysical processes have to be included in order to obtain the expected quasi-steady state of the cloud-topped MBL. Ignoring only collision/coalescence or in addition to this also the gravitational settling of the particles yields in both model configurations a completely different time evolution of the boundary layer. Hence, it is concluded that even with the simple parametrization approach of PaStra it is possible to obtain reasonable model results, provided all major cloud microphysical processes are included in the scheme.

The results of the present study have been obtained by embedding MiStra and PaStra in a one-dimensional model of the cloud-topped MBL. Certainly, with this model it is not possible to realistically describe the boundary-layer processes because for this a three-dimensional dynamic model is mandatory. Nonetheless, since usually in NWP and climate models physical processes are simulated separately in each vertical column of the model grid, it is believed that the results obtained with the present single-column model may also be transferred to 
these applications, specifically the need to consider in parametrization schemes of low-level clouds not only condensation/evaporation, but also collision/coalescence and sedimentation. Owing to the extremely high demands of computer resources required for MiStra, at present it is barely possible to implement this cloud scheme in a three-dimensional NWP model. By comparison, the CPU times needed for the MiStra model runs are usually about 300 times as large as those of PaStra.

Acknowledgements Open Access funding provided by Projekt DEAL. This research is partly funded by the Deutsche Forschungsgemeinschaft (DFG Grant Bo 998/15-1).

Open Access This article is licensed under a Creative Commons Attribution 4.0 International License, which permits use, sharing, adaptation, distribution and reproduction in any medium or format, as long as you give appropriate credit to the original author(s) and the source, provide a link to the Creative Commons licence, and indicate if changes were made. The images or other third party material in this article are included in the article's Creative Commons licence, unless indicated otherwise in a credit line to the material. If material is not included in the article's Creative Commons licence and your intended use is not permitted by statutory regulation or exceeds the permitted use, you will need to obtain permission directly from the copyright holder. To view a copy of this licence, visit http://creativecommons.org/licenses/by/4.0/.

\section{References}

Beard KV (1976) Terminal velocity and shape of cloud and precipitation drops aloft. J Atmos Sci 33:851-864 Bobrowski N, von Glasow R, Aiuppa A, Inguaggiato S, Louban I, Ibrahim GW, Platt U (2007) Reactive halogen chemistry in volcanic plumes. J Geophys Res 112:D06311

Bobrowski N, von Glasow R, Giuffrida GB, Tedesco D, Aiuppa A, Yalire M, Arellano S, Johansson M, Galle $\mathrm{B}$ (2015) Gas emission strength and evolution of the molar ratio of $\mathrm{BrO} / \mathrm{SO}_{2}$ in the plume of Nyiragongo in comparison to Etna. J Geophys Res 120:277-291

Bott A (1989) A positive definite advection scheme obtained by nonlinear renormalization of the advective fluxes. Mon Weather Rev 117:1006-1015

Bott A (1997) A numerical model of the cloud-topped planetary boundary-layer: impact of aerosol particles on radiative forcing of stratiform clouds. Q J R Meteorol Soc 123:631-656

Bott A (2001) A new method for the solution of the stochastic collection equation in cloud models with spectral aerosol and cloud drop microphysics. Atmos Res 59:361-372

Bott A, Carmichael GR (1993) Multiphase chemistry in a microphysical radiation fog model—a numerical study. Atmos Environ 27A:503-522

Bott A, Trautmann T (2002) PaFog — a new efficient forecast model of radiation fog and low-level stratiform clouds. Atmos Res 64:191-203

Bott A, Sievers U, Zdunkowski W (1990) A radiation fog model with a detailed treatment of the interaction between radiative transfer and fog microphysics. J Atmos Sci 47:2153-2166

Bott A, Trautmann T, Zdunkowski W (1996) A numerical model of the cloud-topped planetary boundary-layer: radiation, turbulence and spectral microphysics in marine stratus. Q J R Meteorol Soc 132:27-42

Chaumerliac N, Richard E, Pinty J-P, Nickerson EC (1987) Sulfur scavenging in a mesoscale model with quasi-spectral microphysics: two-dimensional results for continental and maritime clouds. J Geophys Res 92:3114-3126

Clark TL (1973) Numerical modeling of the dynamics and microphysics of warm cumulus convection. J Atmos Sci 30:857-878

Davies R (1985) Response of cloud supersaturation to radiative forcing. J Atmos Sci 42:2820-2825

Driedonks AGM, Duynkerke PG (1989) Current problems in the stratocumulus-topped atmospheric boundary layer. Boundary-Layer Meteorol 46:275-303

Fan J, Leung LR, Li Z, Morrison H, Chen H, Zhou Y, Qian Y, Wang Y (2012) Aerosol impacts on clouds and precipitation in eastern China: results from bin and bulk microphysics. J Geophys Res 117:D00K36

Fu Q (1991) Parameterisation of radiative processes in vertically non-homogeneous multiple scattering atmospheres. PhD dissertation, Department of Meteorology, The University of Utah

Fu Q, Liou KN (1992) On the correlated k-distribution method for radiative transfer in nonhomogeneous atmospheres. J Atmos Sci 49:2139-2156

Grabowski WW, Morrison Hm, Shima S-I, Abade GC, Dziekan P (2019) Modeling of cloud microphysics: Can we do better? Bull Am Meteorol Soc 100:655-672 
Hoppel WA, Fitzgerald JW, Frick GM, Larson RE (1990) Aerosol size distributions and optical properties found in the marine boundary layer over the Atlantic Ocean. J Geophys Res 94:3659-3686

Khairoutdinov M, Kogan Y (2000) A new cloud physics parameterization in a large-eddy simulation model of marine stratocumulus. Mon Weather Rev 128:229-243

Kessler E (1969) On the distribution and continuity of water substance in atmospheric circulations. Meteorological monographs, vol 10. American Meteorological Society, Massachusetts, pp 3457-3491

Khain AP, Beheng KD, Heymsfield A, Korolev A, Krichak SO, Levin Z, Pinsky GM, Phillips V, Prabhakaran T, Teller A, van den Heever SC, Yano J-I (2015) Representation of microphysical processes in cloudresolving models: spectral (bin) microphysics versus bulk parameterization. Rev Geophys 53:247-322

Khain A, Leung LR, Lynn B, Ghan S (2009) Effects of aerosols on the dynamics and microphysics of squall lines simulated by spectral bin and bulk parameterization schemes. J Geophys Res 114:D22203

Kim W, Yum SS, Kim CK (2019) Numerical simulation of sea fog over the Yellow Sea: comparison between $\mathrm{UM}+$ PAFOG and WRF + PAFOG coupled systems. Asia Pac J Atmos Sci. https://doi.org/10.1007/ s13143-019-00134-9

Klein SA, Hartmann DL (1993) The seasonal cycle of low stratiform clouds. J Clim 6:1587-1606

Kogan YL (1991) The simulation of a convective cloud in a 3D model with explicit microphysics. Part I: model description and sensitivity experiments. J Atmos Sci 48:1160-1188

Koschmieder H (1924) Theorie der horizontalen Sichtweite. Beitr Phys Atmos 12:33-53

Lacis A, Oinas V (1991) A description of the correlated k-distribution method for modelling nongray gaseous absorption, thermal emission, and multiple scattering in vertically inhomogeneous atmospheres. J Geophys Res 96:9027-9063

Lee H, Baik JJ (2018) A comparative study of bin and bulk cloud microphysics schemes in simulating a heavy precipitation case. Atmosphere 9:475-492

Lim K-SS, Hong SY (2010) Development of an effective double-moment cloud microphysics scheme with prognostic cloud condensation nuclei $(\mathrm{CCN})$ for weather and climate models. Mon Weather Rev 138:1587-1612

Loughlin PE, Trautmann T, Bott A, Panhans WG, Zdunkowski W (1997) The effects of different radiation parametrizations on cloud evolution. Q J R Meteorol Soc 123:1985-2007

Lynn BH, Khain AP, Dudhia J, Rosenfeld D, Pokrovsky A, Seifert A (2005) Spectral (bin) microphysics coupled with a mesoscale model (MM5). Part I: model description and first results. Mon Weather Rev $133: 44-58$

Masbou M (2008) LM-PAFOG: a new three-dimensional fog forecast model with parametrised microphysics. Océan, Atmosphère. Université Blaise Pascal, Clermont-Ferrand, p 180

Mellor GL, Yamada T (1982) Development of a turbulence closure model for geophysical fluid problems. Rev Geophys Space Phys 20:851-875

Milbrandt JA, Yau MK (2005) A multimoment bulk microphysics parameterization. Part II: a proposed threemoment closure and scheme description. J Atmos Sci 62:3065-3081

Morrison H, Curry JA, Khvorostyanov VI (2005) A new double-moment microphysics parameterization for application in cloud and climate models. Part I: description. J Atmos Sci 62:1665-1677

Morrison H, Gettelman A (2008) A new two-moment bulk stratiform cloud microphysics scheme in the community atmosphere model, version 3 (CAM3). Part I: description and numerical tests. J Clim 21:3642-3659

Müller MD, Masbou M, Bott A (2010) Three-dimensional fog forecasting in complex terrain. Q J R Meteorol Soc 136:2189-2202

Nickerson EC, Richard E, Rosset R, Smith DR (1986) The numerical simulation of clouds, rain, and airflow over the Vosges and Black Forest mountains: a meso-B model with parameterized microphysics. Mon Weather Rev 114:398-414

Pechtl S, Schmitz G, von Glasow R (2007) Modelling iodide-iodate speciation in atmospheric aerosol: contributions of inorganic and organic iodine chemistry. Atmos Chem Phys 7:1381-1393

Pruppacher HR, Klett JD (1997) Microphysics of clouds and precipitation. Kluwer Academic Publishers, Dordrecht, p 954

Smith DKE, Renfrew IA, Price JD, Dorling SR (2018) Numerical modelling of the evolution of the boundary layer during a radiation fog event. Weather 73:310-316

Sundqvist H, Berge E, Kristjansson JE (1989) Condensation and cloud parameterization studies with a mesoscale numerical weather prediction model. Mon Weather Rev 117:1641-1657

Twomey S (1959) The nuclei of natural cloud formation part II: the supersaturation in natural clouds and the variation of cloud droplet concentration. Geofisica Pura e Applicata 43:243-249

von Glasow R, Sander R, Bott A, Crutzen PJ (2002) Modeling halogen chemistry in the marine boundary layer: 1. Cloud-free MBL. J Geophys Res 107:4341 
Wærsted EG, Haeffelin M, Steeneveld G-J, Dupont J-C (2019) Understanding the dissipation of continental fog by analysing the LWP budget using idealized LES and in situ observations. Q J R Meteorol Soc 145:784-804

Zhu P, Bretherton CS, Kohler M, Chen A, Chlond A, Geng Q, Austin PH, Golaz J-C, Lenderink G, Lock A, Stevens B (2005) Intercomparison and interpretation of single-column model simulations of a nocturnal stratocumulus topped marine boundary layer. Mon Weather Rev 133:2741-2758

Publisher's Note Springer Nature remains neutral with regard to jurisdictional claims in published maps and institutional affiliations. 